Historic, archived document

\author{
Do not assume content reflects current \\ scientific knowledge, policies, or practices.
}



USDA, National Agricultural Library

NAL Bldg

10301 Baltimore Blvd

Eeitsville, MD 20705-2351 


\section{Costs of Sequestering Carbon Through Tree Planting and Forest Management in the United States}

Robert J. Moulton

Economist

Cooperative Forestry

State and Private Forestry

USDA Forest Service

Washington, DC 20090

Kenneth R. Richards

Graduate Fellow

University of Pennsylvania

Philadelphia, PA 19104

U.S. Department of Agriculture

Forest Service

General Technical Report WO-58

December 1990 



\begin{abstract}
One approach to limiting the buildup of carbon dioxide $\left(\mathrm{CO}_{2}\right)$ in the atmosphere is to scquester carbon in forests. Several reports have estimated the amount of tree planting and the associated costs that would be required to significantly effect the net release of $\mathrm{CO}_{2}$, but they have largely been "back of the envelope" calculations. This report employs detailed data on actual planting practices, amounts of marginal agricultural land, average merchantable timber yields, historic rental rates, and the ratio of total ecosystem carbon to timber carbon to calculate the incremental amount of carbon that could be sequestered by a rural tree planting and forest management program in the United States. Marginal and total cost curves indicate the relation between costs and the extent of the sequestering program.
\end{abstract}

\title{
Highlights
}

- An extensive tree planting and forest management program could sequester as much as 807 million short tons (56.4 percent of the current annual U.S. $\mathrm{CO}_{2}$ releases) at an annual cost of $\$ 19.5$ billion.

- A program to reduce U.S. net emissions of $\mathrm{CO}_{2}$ by 20 percent would involve 138.4 million acres and cost $\$ 4.5$ billion per year, or an average of $\$ 15.73$ per short ton.

- The costs of carbon sequestering range from $\$ 5.26$ to $\$ 43.33$ per ton.

- Some of the least costly opportunities for carbon sequestering are on forestland and marginal pastureland, although the largest portion of the carbon capture in a program involving reductions of 10 percent or more must be on marginal cropland.

- The geographic distribution of marginal land indicates that such a planting program would be largely concentrated in the Southeast, Appalachia, and the Gulf States.

\section{Acknowledgments}

The authors acknowledge the useful review comments by George Peterson, USDA Forest Service, Rocky Mountain Station, and William Kurtz, School of Forestry, Fisheries and Wildlife, University of Missouri-Columbia. Also, Researcher Michael Fosberg, USDA Forest Service, Washington, D.C., assisted with the development of carbon factors for wood. 


\section{Contents}

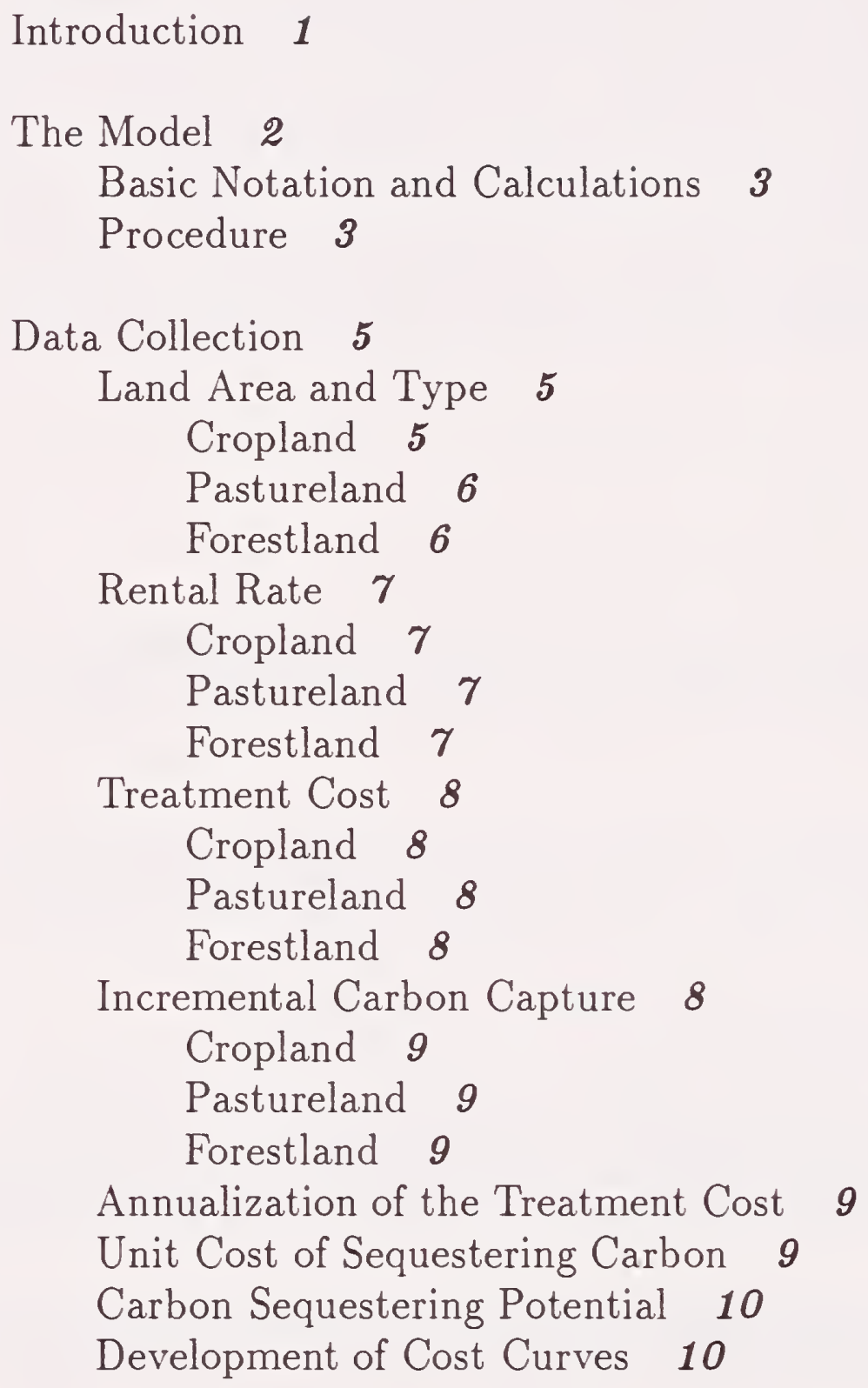

Results and Discussion 11

Limitations of the Analysis 13

References $\mathbf{1 5}$

Appendix A-Tables 17

Appendix B-Figures 44 


\section{Introduction}

While the U.S. Government is studying the science of global climate change, it also is evaluating policy options for affirmative action to reduce risks associated with the greenhouse effect. The principal ways to decrease the emissions of carbon dioxide $\left(\mathrm{CO}_{2}\right)$, the primary contributor to the greenhouse effect, are increasing energy efficiency and switching to nonfossil or low-carbon fuels. These changes may be achieved directly through Government intervention and regulation or indirectly through taxation and related marketable permits.

Alternatively, the Government may wish to consider achieving a portion of its $\mathrm{CO}_{2}$ reduction goals by considering the effect that tree planting and modified forest practices could have on net emissions (that is, the total $\mathrm{CO}_{2}$ emissions less the $\mathrm{CO}_{2}$ sequestered in new forest plantings). To evaluate this forestry potential, the Government should compare the cost of carbon sequestering through tree planting with the cost of carbon cmissions avoidance achieved through investments in energy efficiency and alternative energy sources. While there have been several studies that have evaluated the costs of carbon sequestering (Dudek 1988, Marland 1988, Sedjo 1989), their analyses generally have not considered that, as with most production or extraction processes, there is an increasing marginal cost of sequestering carbon.

This report examines the potential contribution that a large-scale rural tree planting and forest management program could make toward reducing net $\mathrm{CO}_{2}$ emissions in the United States. The land areas in the hypothetical program include economically marginal and environmentally sensitive croplands and pasturelands, as well as forestlands held by private owners other than the forest industry.

Trees would be established on agricultural lands principally by planting trees, although direct seeding would be used in some instances (for example, certain bottomland hardwood species). For existing forestlands, both tree planting and natural regeneration methods would be used to treat poorly stocked stands of trees. Other practices for forestlands include the elimination of indiscriminate livestock grazing and timber harvesting, both of which result in damaged and understocked timber stands, and the replacement of decadent trees with faster growing, younger trees.

Public lands are not considered in this report, in large part because the public ownership of croplands and pasturelands is negligible. The public does control a large and important range resource, but trees are not the dominant form of natural vegetation on rangelands. Therefore, these lands offer comparatively few opportunities for large-scale forestry programs. Likewise, public forestlands offer only a limited opportunity for expanded reforestation because, as a matter of law and policy, regeneration is already taking place on these lands following timber harvests, fires, and other disturbances. The forest industry in the United States in recent decades also has been very active in managing forestlands for increased productivity.

The data regarding planting and management costs and mix of tree species are from practices developed jointly by the U.S. Department of Agriculture (USDA) Forest Service and State foresters and approved 
by county Agricultural Stabilization and Conservation (ASC) committees. As such, these calculations comprise the most detailed, and perhaps realistic, analysis available of the costs of and potential for $\mathrm{CO}_{2}$ sequestration through tree planting.

The primary focus of this report is on the direct social costs of such a program-the sum of the full cost of establishing trees and the market rental value of the land without consideration of whom would bear the cost (Government or private interests) or how that burden would shift over time. These costs are projected over a period of 40 years, which is within the lifespan of all tree species considered. Some species, of course, are commonly grown for periods of more than 80 years. However, 40 years was considered to be a reasonable planning horizon, given the expansion in scientific knowledge concerning the phenomena of global climate change, improvements in the efficiency of energy use, and such that are likely to occur over the next 40 years.

Because of the 40-year planning horizon, questions relating to carbon flows associated with the final dispositions of timber stands, including timber harvesting and carbon storage in forest products, are not addressed in this report.

The principal result of this analysis is the production of two cost curves for the fixation of carbon through tree planting and forest management. The first is a total cost curve that shows the total annual cost of a program associated with a given level of annual carbon sequestering. The second is a marginal cost curve that is used for comparing the costs of carbon sequestering with the costs of carbon emissions reductions. This allows the policy analyst to examine the cost per ton of carbon sequestered, at the margin, of a given size of program. 


\section{The Model}

Thic model employed for developing the cost curves was very simple.

\section{Basic Notation and Calculations}

The following is the basic notation used in the model:

$$
\begin{aligned}
L A^{i} j= & \text { acres of land type } i \text { in farm } \\
& \text { production region } j, i=1 \ldots x, \\
& j=1 \ldots y . \\
R^{i} j= & \text { annual rental cost in dollars per } \\
& \text { acre of land type } i \text { in region } j . \\
P^{i} j= & \text { tree planting/treatment cost in } \\
& \text { dollars per acre (that is, capital } \\
& \text { cost) on land type } i \text { in region } j . \\
Y^{i} j= & \text { annual incremental yield (cubic } \\
& \text { feet per acre per year) of } \\
& \text { merchantable wood on land } \\
& \text { type } i \text { in region } j . \\
K^{i}= & \text { conversion factor (dimensionless) } \\
& \text { for the ratio of incremental } \\
& \text { increase in carbon in forest } \\
& \text { ecosystem (entire tree, soil, surface } \\
& \text { litter, and understory growth) to } \\
& \text { incremental increase in carbon in } \\
& \text { merchantable wood on land type } \\
& i . \\
D^{i} j= & \text { density (tons per cubic foot) of } \\
& \text { carbon in the merchantable wood } \\
& \text { grown on land type } i \text { in region } j .
\end{aligned}
$$

The annual incremental carbon $(C)$ uptake pcr acre on land type $i$ in region $j$ is calculated as:

$$
C^{i} j=Y^{i} j K^{i} D^{i} j
$$

The potential total national carbon $(T C)$ uptake is:

$$
T C=\sum_{i} \sum_{j}\left[L A^{i} j\right]\left[C^{i} j\right]
$$

The cost $(T \$)$ associated with reaching the total national carbon uptake is:

$$
T \$=\sum_{i} \sum_{j} L A^{i} j\left[R^{i} j+A(r, n) P^{i} j\right]
$$

where $A(r, n)$ is the annualized cost of the capital investment $P$, spread over the $n$ years of the project life, at a discount rate of $r$.

The average cost per ton of carbon is simply:

$$
A C=T \$ / T C
$$

Carbon can be converted to $\mathrm{CO}_{2}$ on a weight basis by multiplying by a factor of 3.667 , derived by dividing the molecular weight of carbon dioxide (44) by the molecular weight of carbon (12).

\section{Procedure}

The procedure involved the following six steps:

1. For each of the 10 USDA farm production regions (figure 1 in appendix B), identify and list potential program land areas by land type, segregating according to relevant dimensions (for example, soil, region, climate, erodibility, slope, and current use and condition).

2. Match each land type with an appropriate forestry treatment, such as planting, natural regeneration, and so forth, and with an appropriate mix of species.

3. For each land type in each region, determine the likely rental cost per acre.

4. For each land type in each region, determine the treatment cost and rental cost per acre. 
5. For each land type in each region, with its associated forestry treatment, determine the expected incremental annual yield of merchantable wood per acre. The total incremental carbon yield per acre is derived by multiplying the merchantable wood figure by a conversion ratio that may be land type specific. Each of the forestry treatments will have a certain mix of species, and each of those species will have a specific density of carbon. The product of the incremental merchantable wood yield, the specific carbon density of the wood, and a factor relating carbon in merchantable wood to total forest ecosystem carbon determine the carbon fixation rate for each land type in each region.

6. Calculate the gross carbon fixation costs as:

[Capitalized planting costs + rent]/carbon fixation rate.

The model thus far provides only total yields and total and average costs of a program that uses all marginal lands-the largest possible program. The effect on total and marginal costs of limiting the size of the program may be calculated as follows:

1. By arranging each land type in each region $\left(L A^{\mathrm{i}} j\right)$ in ascending order according to its associated carbon fixation cost, the land areas that capture carbon most cheaply are at the top of the list and the most expensive are at the bottom.

2. The marginal cost curve is derived by plotting the carbon fixation cost $(\$$ per ton) in the ascending list against the cumulative tons sequestered.

3. The total program cost of a given amount of carbon sequestering is derived by plotting the cumulative cost $($ cost $=$ [\$ per ton] x [tons per acre] x [acres in $\left.L A^{\mathrm{i}} j\right]$ ) against the cumulative tons sequestered. 


\section{Data Collection}

The data were largely derived from USDA sources, such as the Soil Conservation

Scrvice National Resources Inventory (NRI), Economic Research Service land rental data, and Agricultural Stabilization and Conservation Service reports and computer files for the Conservation Reserve Program (CRP). The tables referenced in the following subsections are in Appendix A.

\section{Land Area and Type}

The target acres are economically marginal and environmentally sensitive croplands and pasturelands and non-Federal forestlands on which growth rates could be increased. Marginal and environmentally sensitive agricultural lands were defined by the use of soil erosion rates in the current land use and by the land's suitablity for agricultural use according to its land capability class (LCC).

One of the criteria for selecting land was soil loss tolerance, $T$, which is the maximum average annual rate of soil loss that a specific soil can sustain without suffering a decline in its long-term productivity. The value of $T$ ranges from 1 ton to 5 tons of soil loss per acre per year, but it is 5 tons per acre per year for about 70 percent of all soils.

Agricultural lands also were evaluated on the basis of the eight classes of land ( $I$ to VIII) in the Land Capability Classification System, which groups soils according to their ability to produce commonly cultivated crops and pasture plants without degradation or productivity loss. Class I soils are the best and have no severe limitations. Classes II through VIII indicate progressively greater limitations and narrower choices for agricultural use. All of the classes except I arc divided into subclasses to indicate the dominant limitation for agricultural use. Those subclasses are "e," where erosion or damage from erosion is the dominant hazard; "w," to indicate excess water; "s," to indicate limiting soil conditions such as shallowness, stoniness, or salinity; and "c," where climate is the major limitation. For CRP, a combination of the measures has been used to determine eligibility for inclusion (USDA ASCS 1989a, p. 8).

Subclass "w" soils are of special interest to this study because of their potential to contribute to the pollution of surface water and groundwater supplies when they are used in agricultural production. While subclass "w" soils, hereafter often referred to as "wet soils," include wetlands, wet soils influence a much larger area of land that is wet because of poor soil drainage, high water tables, or flooding.

Cropland-Table 2 in appendix A lists the potential cropland area by State and region. There are three types of cropland that could be included beneficially in a tree planting program: (1) land eroding at rates greater than the tolerable rate, $T$; $(2)$ land in LCC $\mathrm{V}$ to VII; and (3) land classified as wet soil. The areas of highly erodible land, in the second column of Table 2 are drawn from USDA SCS 1989b, appendix table 10. The cropland in LCC V to VII, the third to fifth columns of table 2, is from Resources Conservation Act (RCA) Appendix table 3a. However, these figures must be adjusted to avoid double counting with the erodible land in the second column.

There are 19.3 million acres of U.S. land in LCC V to VII (USDA SCS 1987, table 25b), not including Alaska and the Caribbean territories. Of these acres, 7.4 million have already been included in the erodible land of the second column. Assuming that the 62 percent figure can be applied uniformly throughout the United States, the sixth column shows the sum of the third through fifth columns, adjusted down by 38 percent. 
The figures for wet cropland in the seventh column of table 2 are taken from the Draft RCA appraisal (USDA SCS 1989b, p. 11-9, table 11-5). There is likely very little double counting with the previous columns because wet soils are generally on relatively level land, which would not figure prominently in the erodible land or in the LCC V to VII.

Pastureland-Table 3 lists the potential pastureland area by State and region. As with cropland, this analysis recognizes three types of pastureland that could be bcneficially included in a tree planting program: (1) land eroding at rates greater than the tolerance rate, $T$; (2) land in $\mathrm{LCC}$ VII and VIII; and (3) land classified as wet soil.

The areas of highly erodible pastureland in the second column of table 3 are drawn from table A4-11 of the Draft RCA Appraisal (USDA SCS 1989b). Land in LCC VII and VIII, the third and fourth columns of table 3 , is from the Second RCA Appraisal (USDA SCS 1989b), appendix table $3 \mathrm{~b}$. As with cropland, these were adjusted to reflect land already accounted for as erodible land in the second column. There are 9.8 million acres of LCC VII and VIII pastureland in the United States, of which 38 percent is included in the second column. Assuming this figure is constant across the States, the third to fifth columns reflect the 62 percent of LCC VII and VIII that is not reflected in erodible lands. There is a total of 116.4 million acres of pastureland in LCC II, III, IV, and VI in the United States, of which 25.6 million, or 22 percent, is wet soils (USDA ASCS 1989a, table II-A). Based on the assumption that this rate is constant across all States, figures for wet pastureland were derived (USDA SCS $1989 \mathrm{~b}$, appendix table $3 \mathrm{~b})$. The results are presented in the sixth through tenth columns in table 3 .

Forestland-Forestland area, listed in table $\$$, is categorized as either grazed or ungrazed.
The marginal areas of these two categories were further classified according to which of the following three treatment types was most appropriate:

1. Planting trees-These stands are in such poor condition that there is no practical option but to replant. This land may be dominated by brush and scrub growth that precludes the natural establishment of trees, or there may be no natural seed source for natural regeneration. The figures for grazed and ungrazed forestland are taken from the fifth column of tables $14 \mathrm{a}$ and 13a, respectively, of NRI Basic Statistics (USDA SCS 1987a).

\section{Improved management of existing stands} (passive management)-The treatment in these areas would consist of placing the land under formal management agreements that require owners to reduce or eliminate grazing and to avoid overharvesting practices that leave the stand so understocked that the growth does not fully utilize the site. This also would involve some erosion control practices. The figures for grazed and ungrazed forestland requiring passive management are from the fourth and seventh columns of tables 14a and 13a, respectively, of the NRI Basic Statistics (USDA SCS 1987a).

\section{Improved management of existing stands} (active management)-These are stands best managed through active steps, such as the removal of cull and other slow-growing trees and soil preparation to promote natural regeneration of vigorous new trees. Figures for these grazed and ungrazed areas were drawn from the sixth column of tables $14 \mathrm{a}$ and $13 \mathrm{a}$, respectively, of NRI Basic Statistics (USDA SCS 1987a). 


\section{Rental Rate}

Annual rental rates are the most subjective (and hence the most difficult to estimate) figures included in the model. The estimates used here are conservative, reflecting the assumption that it will take significant additional incentives to encourage landowners to make long-term commitments to tree planting. Ultimately, only actual implementation of a program will reveal whether these figures are realistic. The figures on which these estimates are based are shown in table 10, "Derivation of Land Rent Figures."

Cropland-The following three sets of data help estimate cropland rental rates under a Federal tree planting program:

1. Conservation Reserve Program rental rates for the first seven signups, from table 4 of the supplement to the CRP Progress Report (USDA ASCS 1990). There are also data for the acres bid and the bid rental rates, as well as the acres contracted and contract rental rates for the first through the fourth signups (table III-A, USDA ASCS 1989a). The U.S. average contracted rental rate for CRP increased steadily from $\$ 42.06$ per acre in the first signup to $\$ 53.38$ per acre in the fourth.

2. Rental rates in the private sector for dry cropland (that is, not irrigated) in 1987 and 1988 (table 3, USDA ERS 1989c). For most States, CRP average rates are above those for the private market.

3. The average purchase or sale value of dry cropland in the private market (table 2, USDA ERS 1989c).

An interesting insight is gained by examining the ratio of average rental to average sale prices for each of the States. That ratio ranges from 0.5 percent to 0.8 percent for States such as Massachusetts, Delaware, and New Jersey and from 9 percent to 11 percent for South Dakota, Nebraska, and Wyoming. The CRP rental rates have been nearly double the private rental rates. If the low ratios in the Northeast are caused by land speculation, it may be very difficult to get landowners to make long-term commitments to tree growing in that region. And the high ratios in the Northern Plains and Mountain regions indicate that it may be less expensive to purchase land for tree growing than to rent it. An alternative explanation for the differences between CRP and market rental rates may lie within the two sets of data. CRP acres tend to be clustered in certain localities where land values and rental rates, in some instances, may not be accurately portrayed by State average rental rates. Also, CRP rental rates are fixed for the 10-year contract period, and farmers may simply be bidding higher to allow for expected increases in market rates over the contract period.

The final estimates of cropland rental rates were, as mentioned above, relatively subjective. They were based primarily on the CRP rental rates, adjusted upward by 10 to 15 percent-to reflect that the most eager renters have already entered the program and adjusted upward an additional 5 to 10 percent for those regions in which land values were very high relative to private rental rates. In no case was the rental rate allowed to exceed 20 percent of the land value.

Pastureland-State-by-State figures for private rental rates on pasturelands were adjusted to estimate program rental rates (table 2, USDA ERS 1989c). The expected rental rate for pastureland was derived by multiplying the expected cropland rental rate by the ratio of private grazing land rental rates to private cropland rental rates.

Forestland-Forestland was expected to have the lowest opportunity cost of any 
land type and was accordingly assigned a rental rate equal to 35 percent of that of the pasturcland for the same region.

\section{Treatment Cost}

Treatment cost per acre, shown in column 3 of table 1, varies according to the land type and the region of the country. The figures include total costs (public plus private) for the entire treatment, which in the case of tree planting includes the seedlings, planting, site preparation, and postplanting treatment and care required to ensure establishment. No allowance was made for subsequent costs that owners may incur for practices such as precommercial thinnings, release cuttings, and pruning. Although such practices may frequently enhance the production of commercial timber products, it does not necessarily follow that the ability of stands to sequester carbon will be increased.

Cropland-The figures in Table 1 for wet and dry cropland treatment costs were derived from the second column of tables 4 and 5, respectively. For each region, the costs reflect a given mix of tree species, based on historical planting patterns. In some regions, costs vary slightly between wet and dry areas because of differences in species mix. For example, although Douglas-fir was the single most important species on the drier erodible cropland in the Pacific region, it is not as prevalent in the wet soils planting in that region because it does not thrive in wet soils.

Species mix and planting practice costs for dry soils were derived from ASCS Conservation Reporting and Evaluation Systems files, based on special runs by the Forest Service. For wet soils, the species were modified according to Forest Service figures (USDA FS 1983a).

Pastureland-The treatment of pastureland is identical to that for cropland, except that additional costs are incurred for initial preparation (soil preparation, weed control, and so on). The fact that treatment costs are generally higher for pastureland than for cropland reflects this additional requirement, as shown in tables 6 and 7 .

Forestland-As mentioned above, the grazed and ungrazed marginal, non-Federal forestland areas can be distinguished as to treatment type required. Each of these treatment costs carries a unique cost figure, as follows:

1. Planting trees-The figures for this activity were derived from Forest Service figures (table 9.4, USDA FS 1988). Because the regions do not correspond exactly to the regions used in this study, some transposition of State cost figures was required.

2. Passive management-This treatment may be as simple as requiring the landowner to close gates, but it also may in some cases require new fencing or other expenses. Expert advice indicated the cost to be approximately $\$ 4$ per acre.

3. Active management-The figures for active management also were derived using the stocking control figures (table 9.4, USDA FS 1988). The derivation of these figures required the same assumptions, transposing, and calculations as the derivation of the planting trees figures.

\section{Incremental Carbon Capture}

Column 4 of table 1 is an estimate of the additional annual uptake of carbon per acre for each region and soil type. It is composed of the product of the following three factors:

1. The incremental gain in cubic feet of merchantable (commercially salable) wood per acre per year (Risbrudt and Ellefson 
1983, table 16; USDA 1983b, Appendix C).

2. The ratio of the carbon contained in the incremental increase in the trees, soil, and surface litter to the carbon contained in the incremental merchantable wood.

3. The carbon density in pounds per cubic foot of wood.

The Forest Service has collected extensive data on the first factor, which varies with the land type, region, and treatment of the area. The figures for the carbon ratio are derived from recent research conducted by the Forest Service (Birdsey 1990a, b). Those conversion factors range from 1.9 (pines planted in Northeast forestland) to 8.4 (spruce planted in various soil types and regions). Specific gravities for wood by tree species were obtained from the Wood Handbook (USDA FS 1987b). The final factor, carbon density, has been estimated by Brown (1988) for a variety of species of trees.

Cropland-The ninth column of tables 4 and 5 represents the annual capture of carbon. These figures are derived by dividing the product of the fourth, sixth, and seventh columns by 2,000 to convert pounds to tons. The wet soils generally have a higher yield of wood than the dry. For example, yields of loblolly pine and slash pine are approximately 20 percent higher in wet soils. While these species adapt to a wide variety of sites, both achieve their optimal growth on wet soils.

Pastureland-Wet and dry pastureland yields of merchantable wood are expected to follow patterns similar to cropland, with a 15 -percent reduction to reflect problems of competing weeds and a generally inferior quality of soil.

Forestland-The incremental carbon yield for forestland was calculated in much the same way as for cropland. For the treatment types "planting trees" and "active management," the incremental yield of merchantable wood was drawn from table 9-4 of USDA (1988). This is shown on a regional basis in the last column of the respective sections in table 8. Each regional yield of merchantable wood for planting trees and active management was distributed among the various species for that region, based on the area weight (the second column) of the species. The merchantable wood yield by species and region is shown in the columns titled "Merch. wood" under the headings "Planting trees" and "Active management" in table 9. The figures for merchantable wood were multiplied by the carbon density figures (the fourth column) and the total carbon ratio (the fifth column) to derive the yield of carbon for planting trees and active management, as shown in table 9. The incremental yield of merchantable wood (and hence carbon) for passive management was estimated as 50 percent of that for active treatment.

\section{Annualization of the Treatment Cost}

To provide comparability to annual rents and annual incremental yields of carbon sequestering, the treatment costs were annualized. A period of 40 years was chosen to reflect a reasonable lifetime for a program of this magnitude. Longer periods would have little effect on the relative contribution of the treatment cost to total cost. An interest rate of 10 percent was assumed, yielding a capital recovery factor of 0.10226 (column 5, table 1). This factor was multiplied by the treatment cost to yield an annual cost equivalent for the treatment cost (column 6, table 1), and this was added to the annual rent, to produce a total annual cost in dollars per acre, shown in column 7 of table 1.

\section{Unit Cost of Sequestering Carbon}

In table 1 , the cost per ton of carbon 
sequestered (column 8) was calculated by dividing the total annual cost per acre (column 7), by tons of carbon per acre per year (column 4) for each region, land type, and soil type. For example, it costs $\$ 37$ per ton to use dry cropland in the Corn Belt to sequester carbon, but it is only $\$ 22$ per ton to use planting on forestland in the Northeast.

\section{Carbon Sequestering Potential}

Column 9 of table 1 shows the total carbon capturing potential of each land type in each region. This was derived by simply multiplying the total land area (column 1) for each land type by the incremental yield per acre for that land type (column 4). This suggests that while only 1.1 million tons of carbon could be captured using the dry pastureland in the Northern Plains region, 105.2 million tons could be captured if all of the marginal wet cropland in the Corn Belt were used.

\section{Development of Cost Curves}

The final cost curves were derived by sorting the various regional land types in ascending order according to their unit cost figures in column 8 of table 1. This configuration helps identify the tree planting areas that provide the least cost capture of carbon, the tons of carbon that can be sequestered at those costs, and the number of acres involved in each area. The results for the initial data and assumptions are shown in table 1A. From this table, two types of cost curves were developed. The total cost curve is a graph of the total cost of a carbon sequestering program as a function of the number of tons of carbon captured. The marginal cost curve is a graph of the marginal cost of an additional ton of carbon capture as a function of the total tons of carbon captured. This helps answer the question: "If we are already capturing 100 million tons of carbon, what would be the cost of capturing an additional ton?" 


\section{Results and Discussion}

The total and marginal cost curves are displayed in figures 2 and 3 , respectively. Along with tables 1 and $1 \mathrm{~A}$ in appendix $\mathrm{A}$, these results lead to the following relevant observations.

- Based on an estimated current annual U.S. net emissions of carbon (in the form of $\mathrm{CO}_{2}$ ) of 1.4 billion short tons per year, a tree planting and management program limited to marginal agricultural and forestland could achieve as much as a 56.4-percent decrease in net emissions.

- The cost of a program to achieve a 56.4-percent reduction would be approximately $\$ 19.5$ billion per year. As shown in table 11, the annual cost of achieving 10-, 20-, and 30-percent reductions would be approximately $\$ 1.7$, $\$ 4.5$, and $\$ 7.7$ billion, respectively.

- The marginal cost of carbon captured in programs designed to reduce net $\mathrm{CO}_{2}$ emissions by 10, 20, 30 and 56 percent is $\$ 16.9, \$ 20.9, \$ 23.6$, and $\$ 43.3$ per ton, respectively.

- As shown in table 11, a least-cost program to reduce net emissions of $\mathrm{CO}_{2}$ by 10 percent would involve approximately 71 million acres. Of this, 22.2 million (31 percent) are pastureland, 36.9 million (52 percent) are forestland, and 11.8 million (17 percent) are cropland (figure 4).

- As shown in table 11, the average cost of achieving 10-, 20-, and 30-percent offsets would be $\$ 12.02, \$ 15.73$, and $\$ 17.91$ per ton, respectively.

- The costs of the program are dominated by land rental costs, with the establishment or planting costs generally constituting less than 40 percent of total annualized costs on the crop and pastureland.

- One area of concern is the extent to which a tree planting program would compete with other productive uses of the land, particularly crop production. First, it must be emphasized that this analysis has been limited in scope to economically marginal and environmentally sensitive croplands, pasturelands, and forestlands on which growth rates of trees could be enhanced. Second, as the results in table $1 \mathrm{~A}$ and figure 4 indicate, the first 10-percent (143 million tons per year) offset would involve relatively little cropland. As indicated in Figure 5 , however, the relatively few acres of cropland that are included at the 200-million-tons-per-year level provide a disproportionate share of the carbon sequestration. This is because of the contribution of relatively inexpensive but productive cropland in the Mountain region. Beyond 200 million tons per year, virtually all of the significant capacity is on cropland.

- Because most of the costs associated with a large-scale planting program are in the rental or land opportunity costs, the effect of the discount rate is not strong. As shown in Figure 6, at 800 million tons per year, lowering the discount rate from 10 percent (which was employed for this analysis) to 4 percent decreases the total annualized costs by approximately

10 percent.

- The relative number of acres used in each region depends on the size of the tree planting program (table 12). For example, a least-cost program designed 
to offset 5 percent of total U.S. $\mathrm{CO}_{2}$ emissions would involve no land from Appalachia, whereas in a 30 -percent reduction program that region would have the highest share of acreage. In contrast, the Pacific region would have more acreage involved in a 5 -percent program than any other region, but its contribution would increase only slightly in a 30 -percent program, making it one of the least significant regions. At no level is a large acreage from the Northeast involved. 


\section{Limitations of the Analysis}

The scope of this analysis is, by design, limited to the direct costs to society, measured in terms of the estimated cxpenditures required for tree planting and other forest practices and the implicit cost-as represented by market rental rates - of foregoing opportunities to continue alternative uses of the land. Such a program, of course, would affect society beyond these direct costs.

Fischman (1990) of the Environmental Law Institute has termed tree planting a no-lose option that provides enough social, environmental, and economic benefits to justify program expenses irrespective of the outcome of the greenhouse debate. Obviously, the scale of any such program would be an important factor. Increases in the scale of tree planting would very likely have a number of external effects, such as changes in soil crosion rates, water quality and water flows, wildlife populations and species composition, and measurable effects on other areas, including farm income and consumer prices for food.

The indirect impacts of CRP and other resource provisions of the 1985 Farm Bill are in some ways analogous to an expanded tree program, and various aspects of these programs have been reported. For example, sec Moulton and Dicks (1987), Robinson (1987), Ribaudo (1989), Moulton and et al. (1989), and Young and Osborne (1990).

Another important feature of the study is that it does not consider the effects of timber harvesting on the carbon budgets of forest ecosystems. This is consistent within the focus of what could be done within an intermediate timeframe to offset atmospheric carbon dioxide and the 40-year planning horizon of the study, during which little harvesting of a final nature would need to occur. Birdsey (1990a) has looked at the release of carbon in harvesting and has related this to the increased rate of carbon dioxide assimulation associated with younger and faster growing replacement forest stands. In addition, Row (1990) has investigated the storage of carbon in forest products.

This analysis also does not consider the startup period for a tree planting program. The assumption has been one of "instant trees" - as if society has committed funds, and there will immediately be several million new acres of trees fixing carbon. In fact, a large-scale effort could take 5 to 20 years simply to plant the trees, depending on the number of acres involved, and then another 5 to 15 years for those trees to be fixing carbon at the rates used in this analysis. This inevitably will bring some costs forward, while delaying the environmental benefits.

There also are limitations to the material that is included in the analysis. As indicated under "Data Collection," the land rental rates have been particularly difficult to estimate. Here, we have attempted to use conservative estimates, 12 to 25 percent higher than the historic CRP rental rates, which, in turn, generally have been considerably higher than the private market rental rates. Notwithstanding, the rental rates, as well as all other estimates of costs, are first-order estimates. Further research should consider nonmarginal changes in costs associated with very large-scale reforestation in a general equilibrium context.

Similarly, the estimates of incremental timber yield are based on the historic performance of each region where the programs have not been designed to maximize carbon capture. With improved genetic strains, changes in the species mix, and management for optimizing $\mathrm{CO}_{2}$ uptake, the yield of carbon capture 
per acre could be improved considerably. Also, while the ratios relating merchantable wood carbon to total carbon in the forest ecosystem are the best available, further research on this critical factor is needed. 


\section{References}

Birdsey, R. 1990a. The carbon cycle impacts of forests and forestry changes. In: Proceedings, North American Conference on Forestry Responses to Climate Change; 1990 May 15-17; Washington, DC: The Climate Institute. (in process)

Birdsey, R. 1990b. Estimation of regional carbon yields for forest types in the United States. Draft manuscript.

Brown, S. 1988. The global carbon cycle. Science 241:1739; September 30.

Dudck, D. 1988. Offsetting new $\mathrm{CO}_{2}$ cmissions. Paper presented at the Annual WEA Int'l Meeting; 1989 June 18-22; Lake Tahoe, CA: Environmental Defense Fund. 22 p.

Fischman, R. 1990. A program lovely as a tree. Environmental Forum 7: March/April 1990.

Marland, G. 1988. The prospect of solving the $\mathrm{CO}_{2}$ problem through global reforestation. DOE Report DOE/NBB-0082. Washington, DC: U.S. Dcpartment of Energy, Office of Energy Research.

Moulton, R.; Dicks, M.R. 1987. Implications of the 1985 Farm Act for Forestry. In: Proceedings, 1987 joint annual meeting of the Southern and Midwest Forest Economists; 1987 April 8-10; Asheville, NC: $163-176$.

Moulton, R.; Hyberg, B.; Hebert, T.; Dicks, M. 1989. The timberland in Conservation Reserve Program and its effect on southern rural economies. In: Proceedings, 1989 Annual Meeting of the Southern Forest Economists; 1989 March 1-3; San Antionio, TX: 144-159.

Ribaudo, M.O. 1989. Water quality benefits from the Conservation Reserve Program. Agric. Ec. Rep. 606. Washington, DC: U.S. Department of Agriculture.

Risbrudt, C.; Ellefson, P. 1983. An economic evaluation of the 1979 Forestry Incentives Program. Station Bulletin 550. University of Minnesota; Agricultural Experiment Station. 55 p.

Robinson, A.Y. 1987. Saving soil and wildlife: The promise of the Farm Act's conservation title. Izaak Walton League of America. June 1987. 62 p.

Row, C. 1990. The carbon cycle impacts of improving forestry products utilization and recycling. In: Proceedings, North American Conference on Forestry Responses to Climate Change; 1990 May 15-17; Washington, DC: The Climate Institute.

Sedjo, R. 1989. Forests to offset the greenhouse effect. Journal of Forestry $87(7): 12-15$; July.

Young, C.E.; Osborne, C.T. 1990. The Conservation Reserve Program, an economic assessment. Agric. Ec. Rep. 626. Washington, DC: U.S. Department of Agriculture.

U.S. Department of Agriculture, Agricultural Stabilization and Conservation Service. 
1990. Supplement I to the Conservation Reserve Program: Progress report and preliminary evaluation of the first two years. Draft report. Washington, DC: U.S. Department of Agriculture.

U.S. Department of Agriculture, Agricultural Stabilization and Conservation Service. 1989a. Conservation Reserve Program: progress report and preliminary evaluation of the first two years. Washington, DC: U.S. Department of Agriculture.

U.S. Department of Agriculture, Soil Conservation Service. 1989b. 2nd Resource Conservation Act appraisal. (Draft). Washington, DC: U.S. Department of Agriculture.

U.S. Department of Agriculture, Economic Research Service. 1989c. Agricultural resources, agricultural land values and markets. Washington, DC: U.S. Department of Agriculture.

\section{U.S. Department of Agriculture, Forest} Service. 1988. An analysis of the timber situation in the United States 1989-2040. Part II: The future resource situation.
(Draft). Washington, DC: U.S. Deparment of Agriculture.

U.S. Department of Agriculture, Soil Conservation Service. 1987a. Basic statistics, National Resources Inventory. Washington, DC: U.S. Department of Agriculture.

U.S. Department of Agriculture, Forest Service. 1987b. Wood handbook: Wood as an engineering material. Agric. Handb. 72. Washington, DC: U.S. Department of Agriculture. 466 p.

U.S. Department of Agriculture, Forest Service. 1983a. Silvicultural systems for the major forest types of the United States. Agric. Handb. 445. Washington, DC: U.S. Department of Agriculture.

U.S. Department of Agriculture, Office of Budget and Program Analysis. 1983b. Conversion of southern cropland to southern pine tree plantings: Conversion for conservation feasibility study. Washington, DC: U.S. Department of Agriculture. 
Appendix A-Tables 


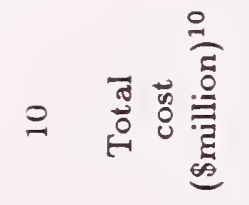

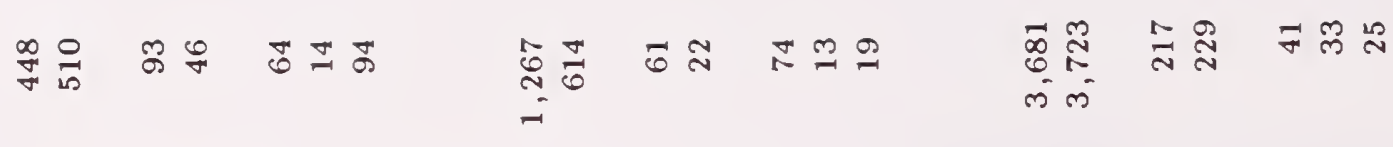

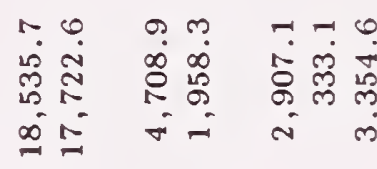

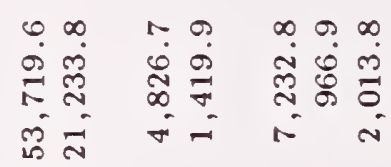

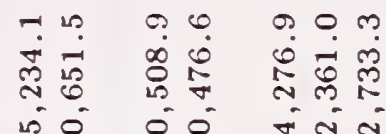

60

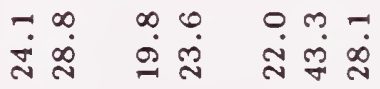

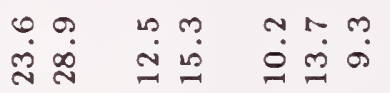

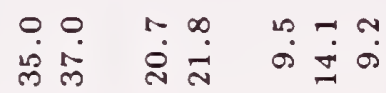

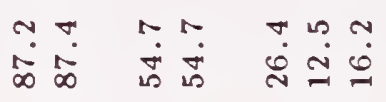

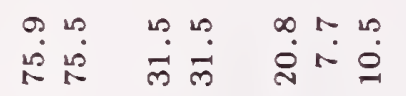

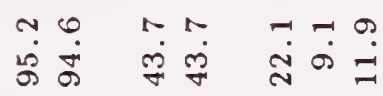

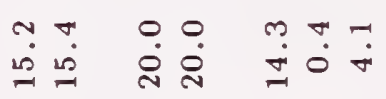

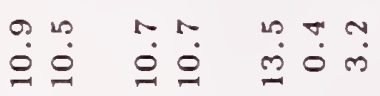

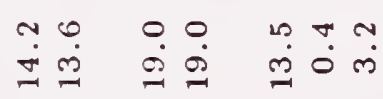

ص

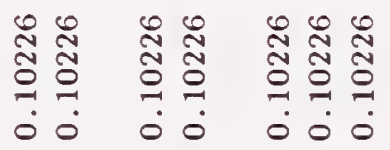

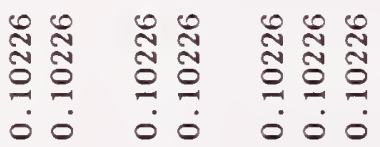

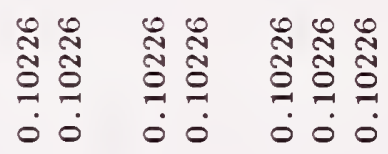

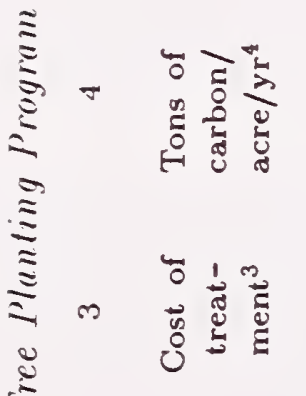

$\overline{0}$

$\stackrel{0}{\because}$

สิ กิ

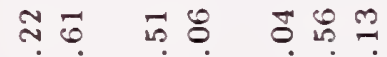

ำ ㅇำ

मांत

लं तं तं

तi na no

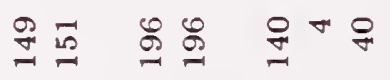

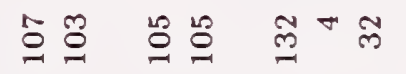

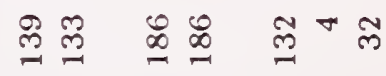

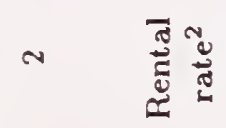

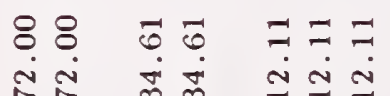

$88 \quad \infty \otimes \quad \infty \sim \infty \sim \infty \sim$

में

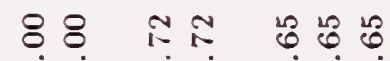

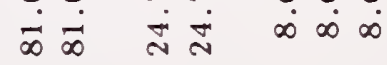

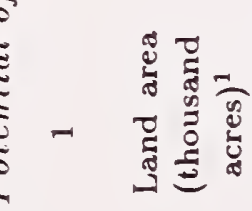

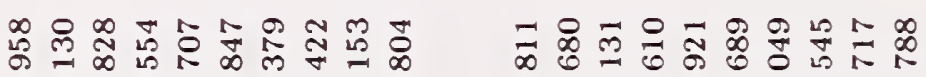

m

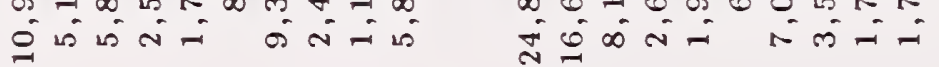

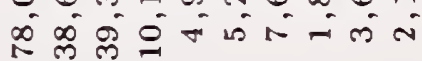

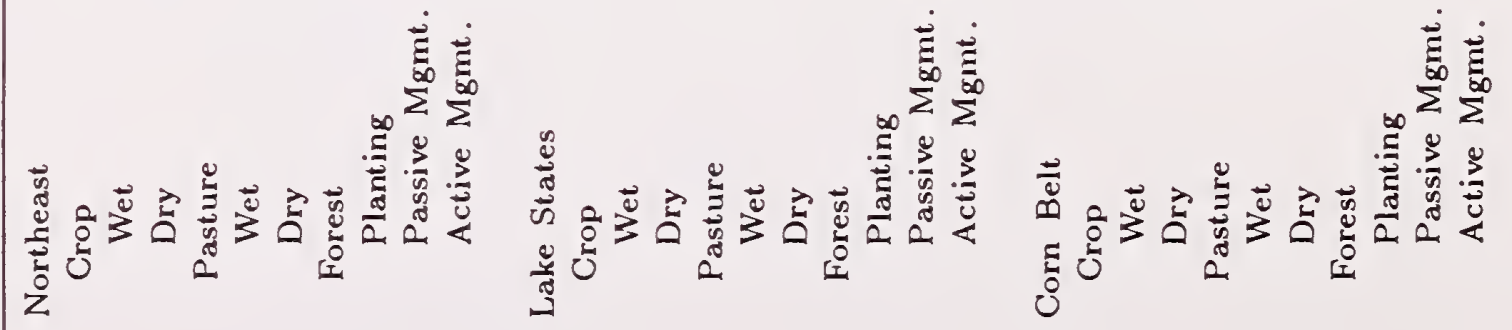




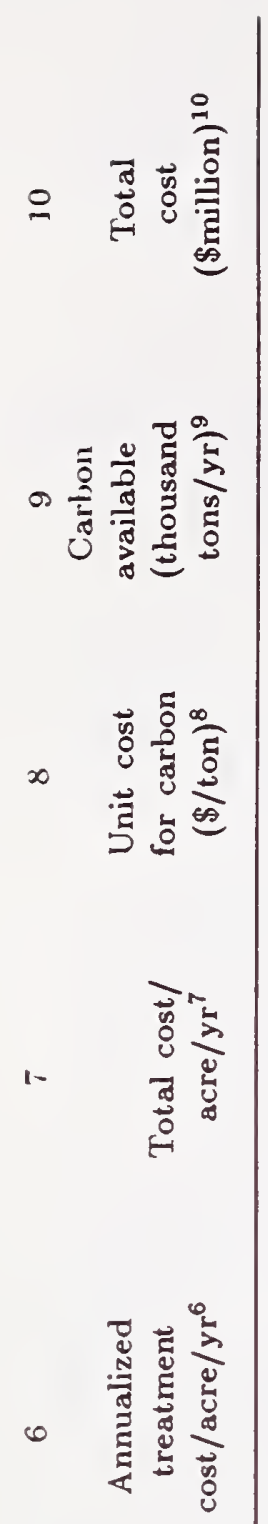

gine

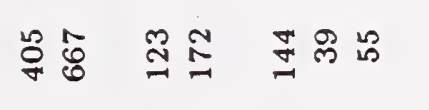

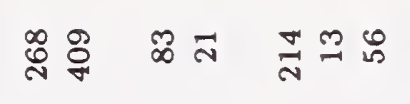

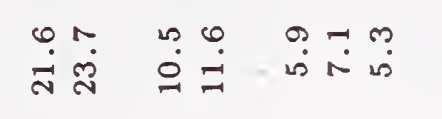

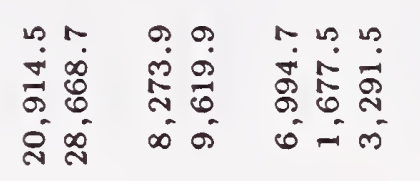

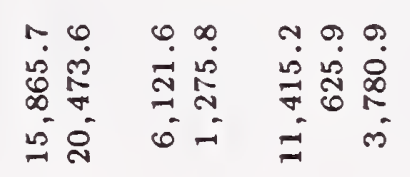

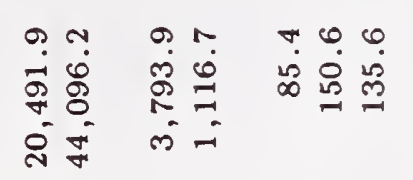

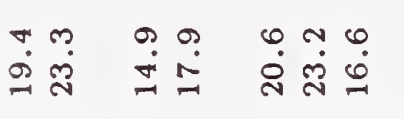

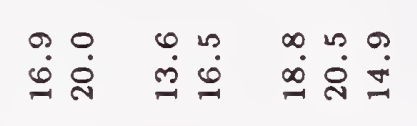

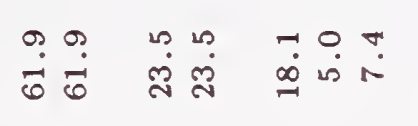

舫荌

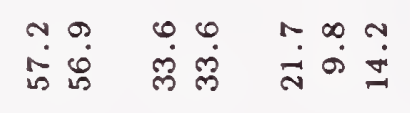

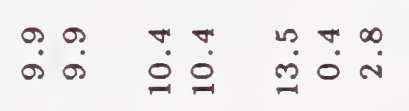

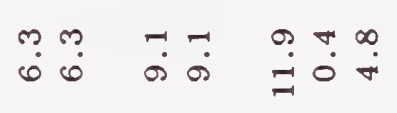

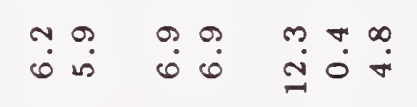

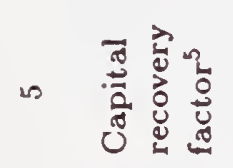

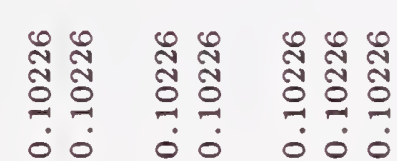

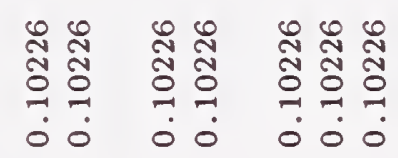

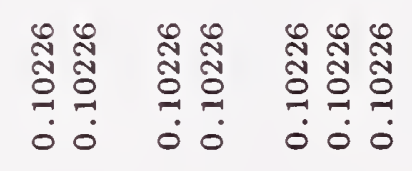

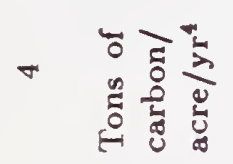

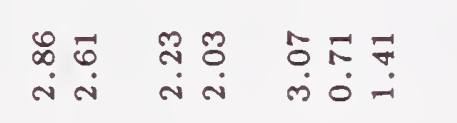

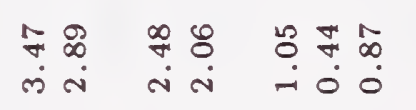

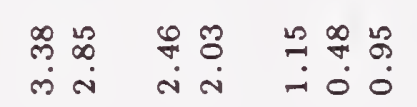

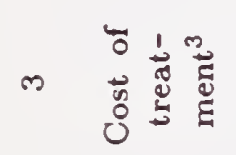

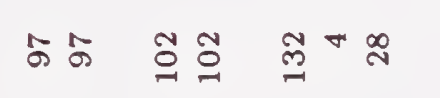

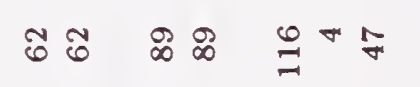

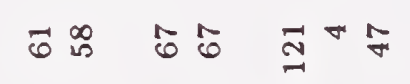

$\sim \quad$ ๑

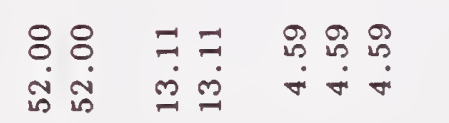

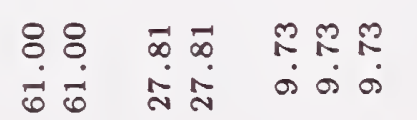

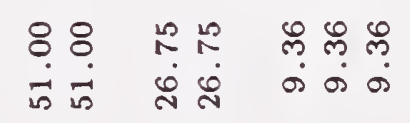

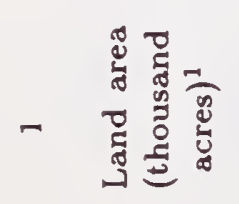

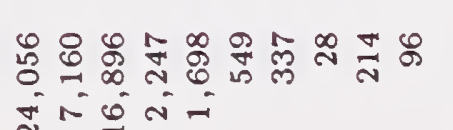

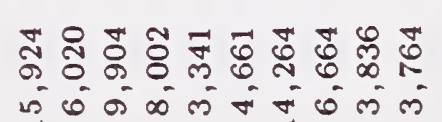

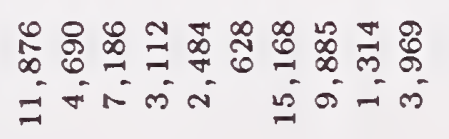

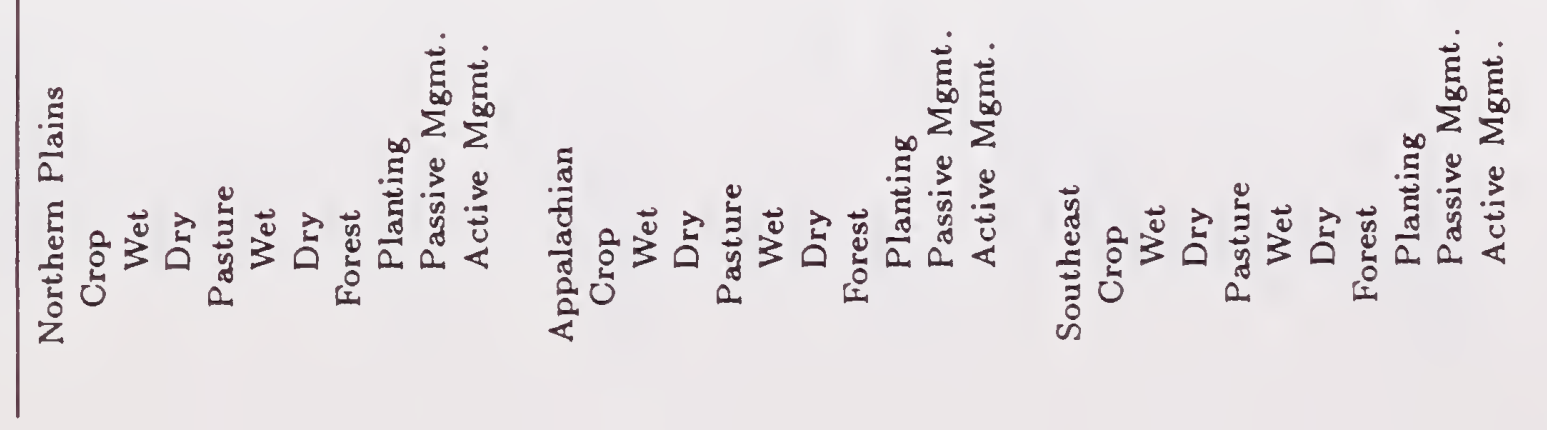




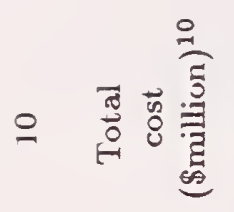

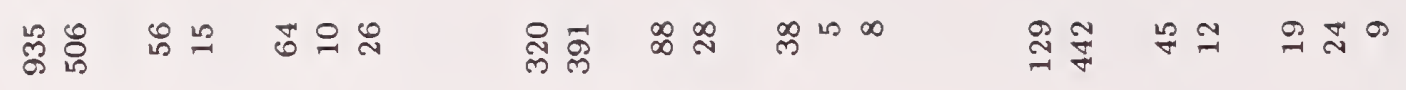

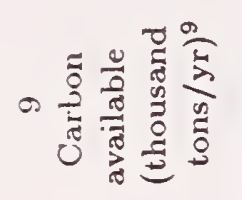

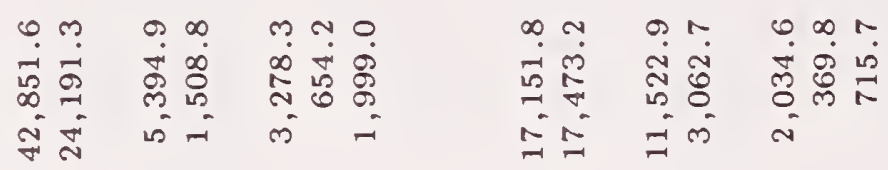

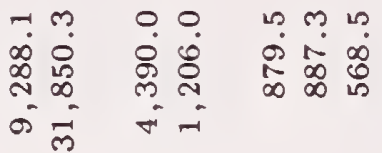

舟宾

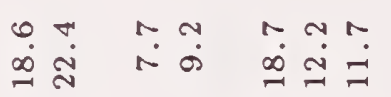

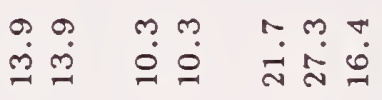

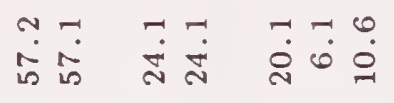

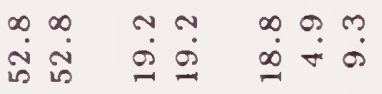

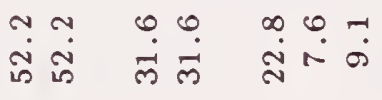

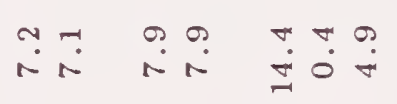

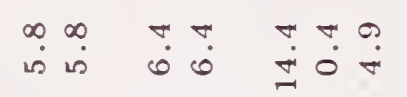

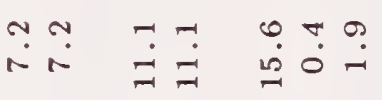

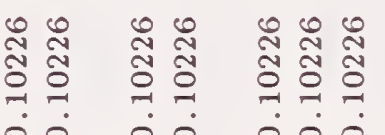

造

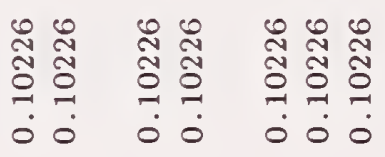

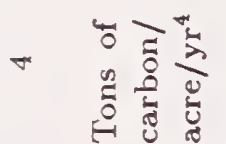

象苗

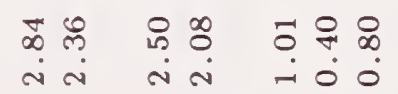

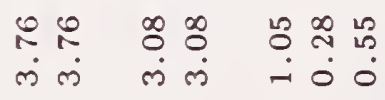

m)

R R R

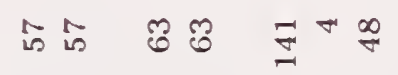

웅 8

$\sim \quad \frac{2}{\pi}$

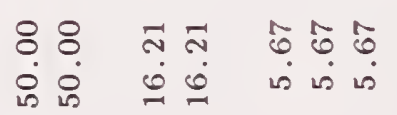

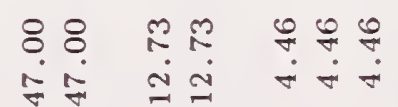

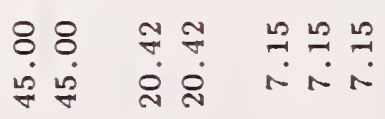

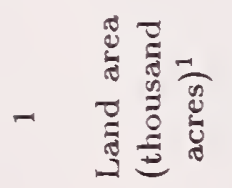

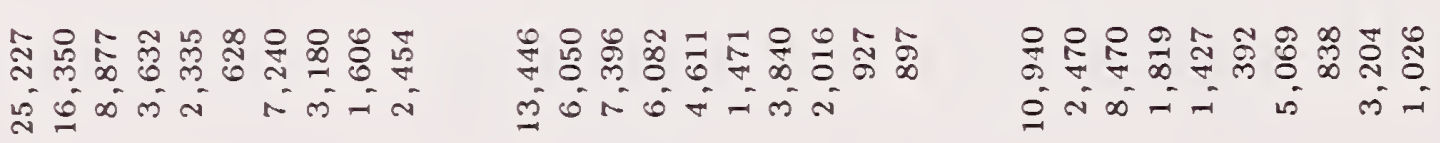

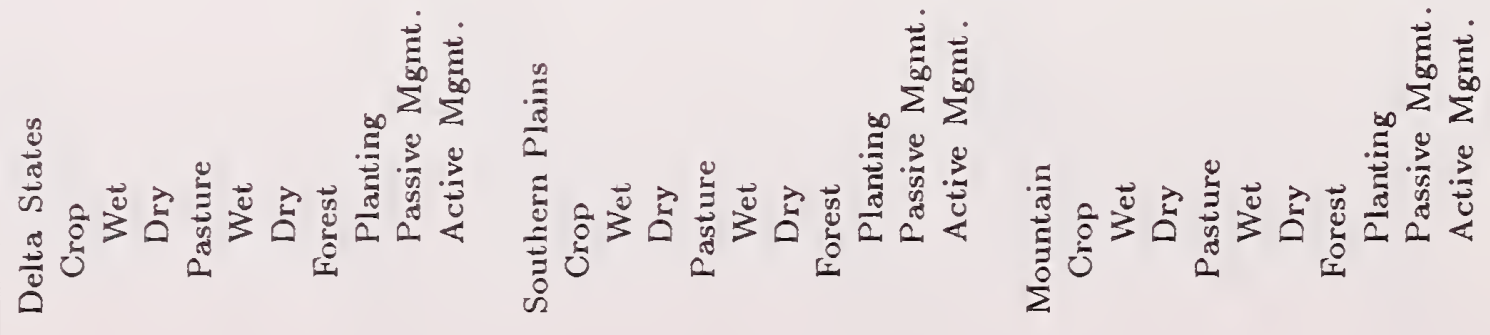


유

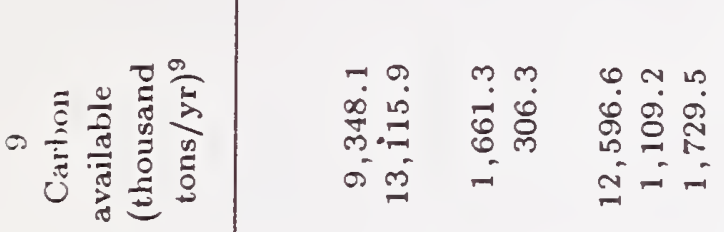

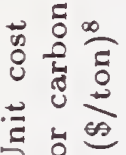

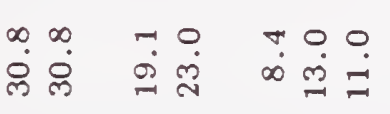

1.

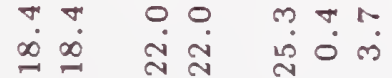

-

N

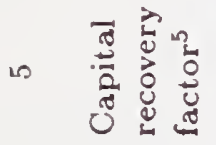

芯芯

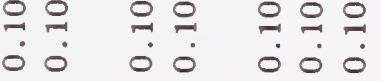

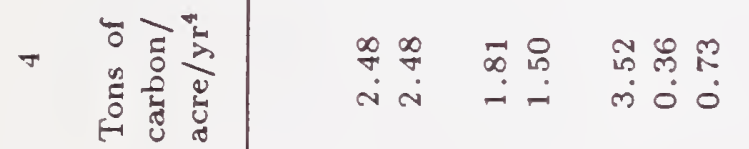

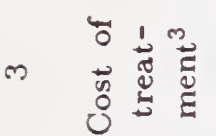

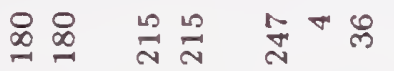

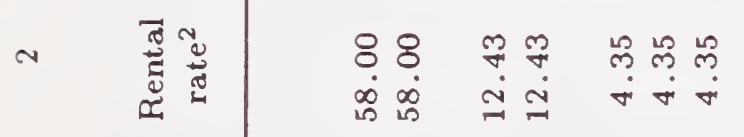

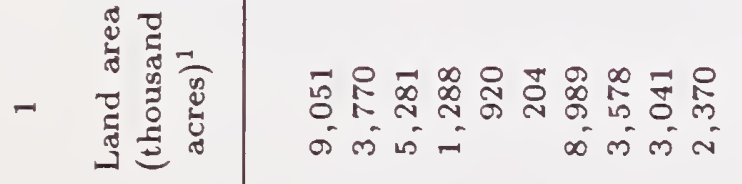

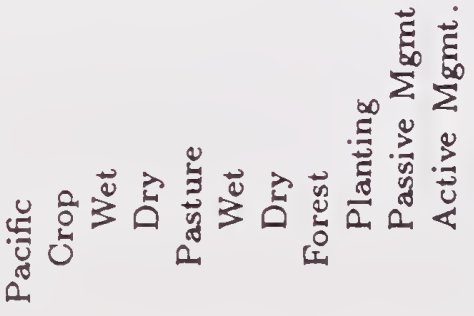




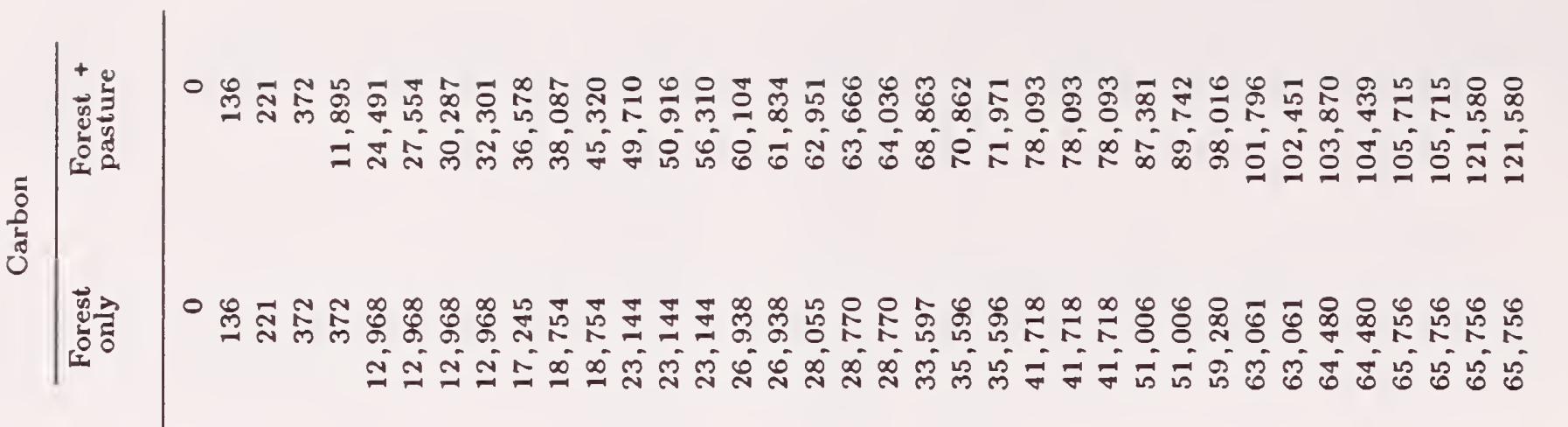

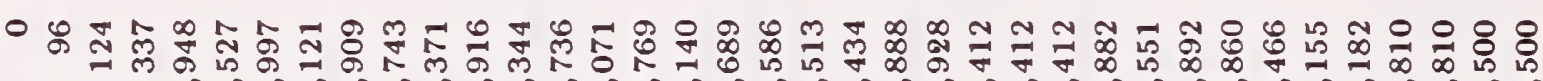
丁

递

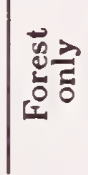

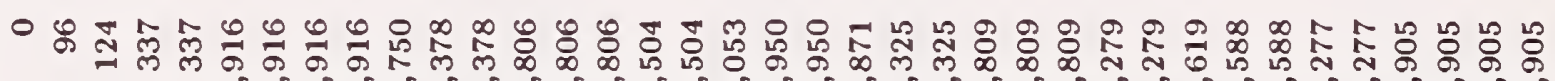

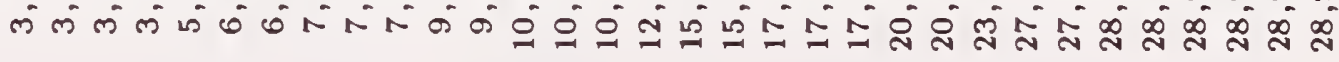

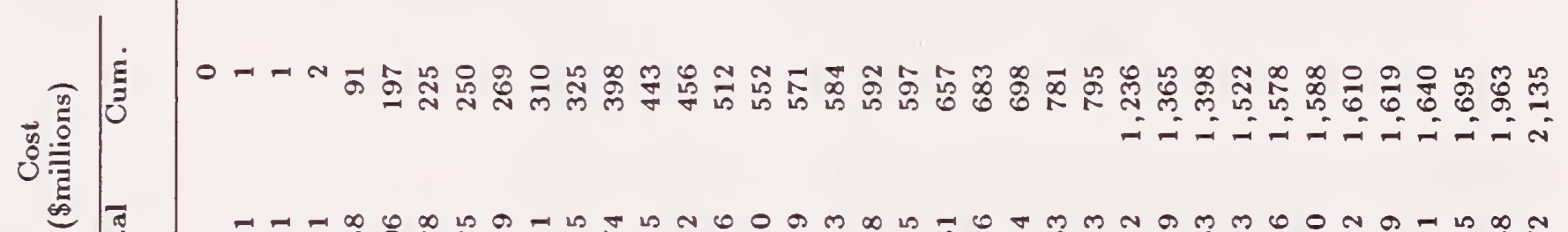

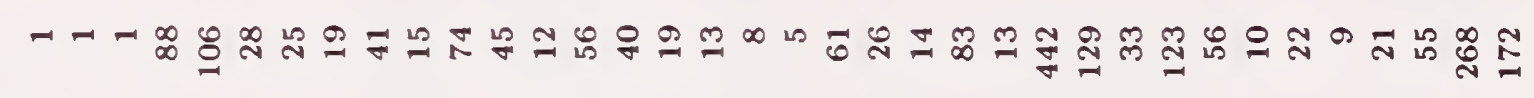

○号

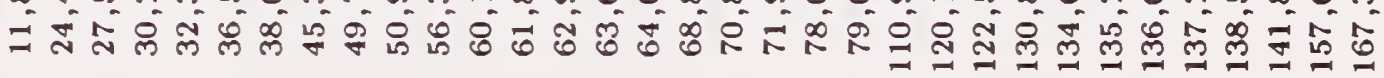

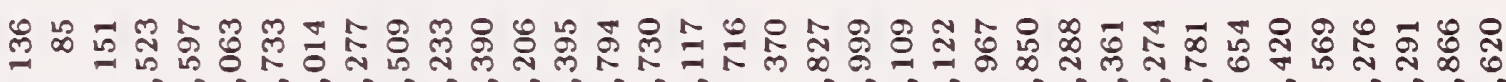

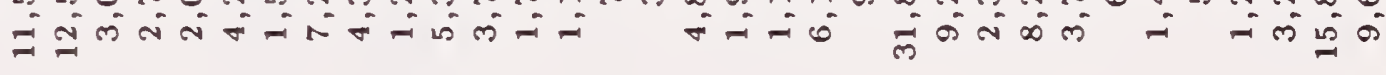

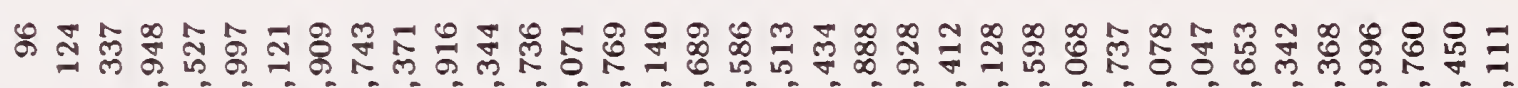

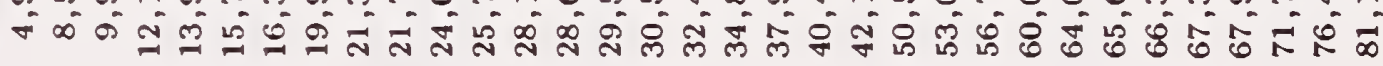
$+\infty$

\&

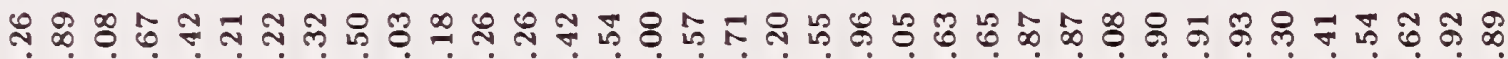

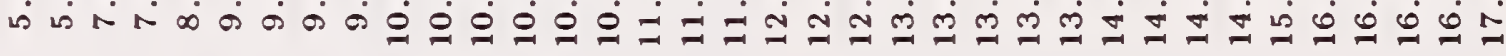




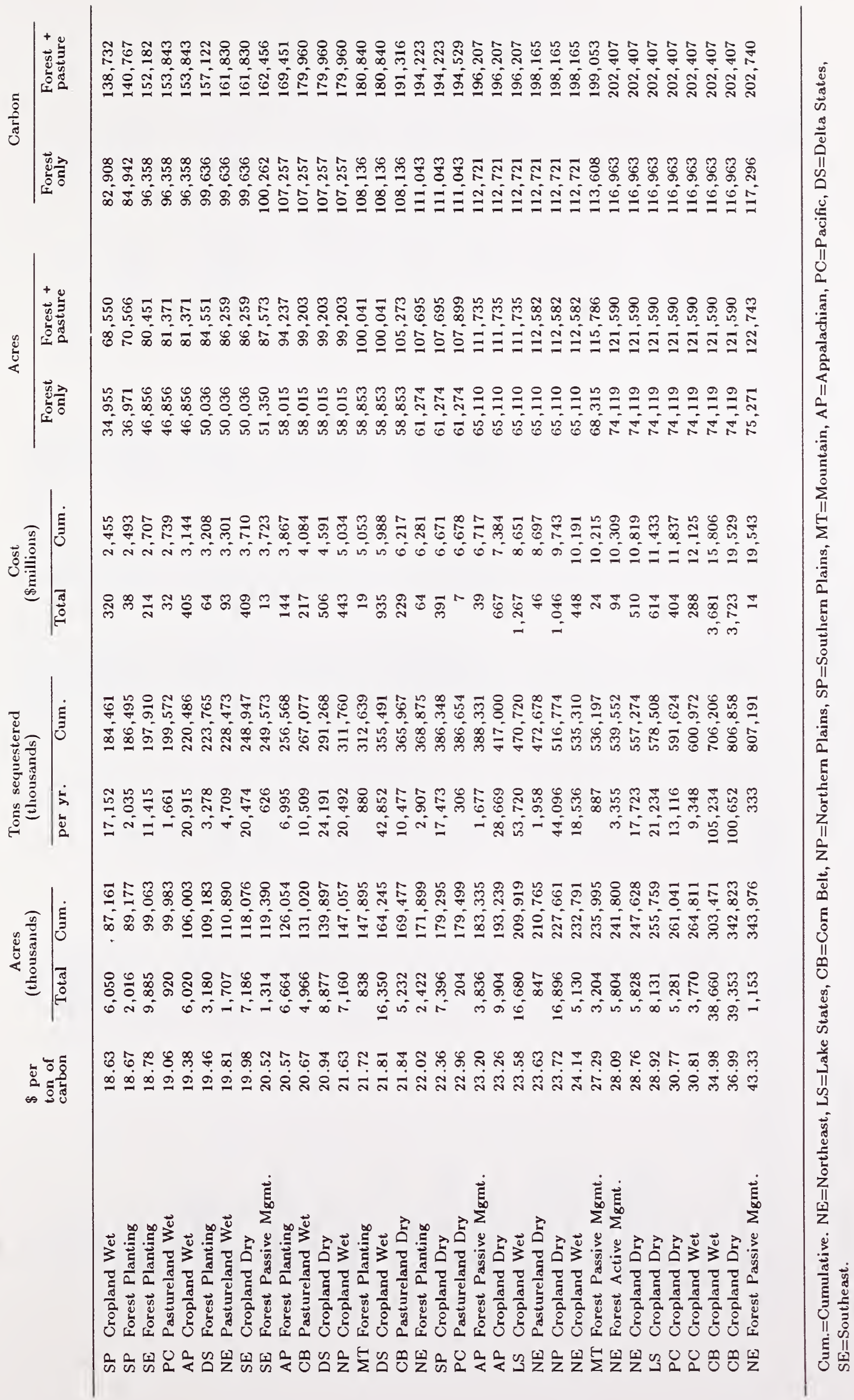




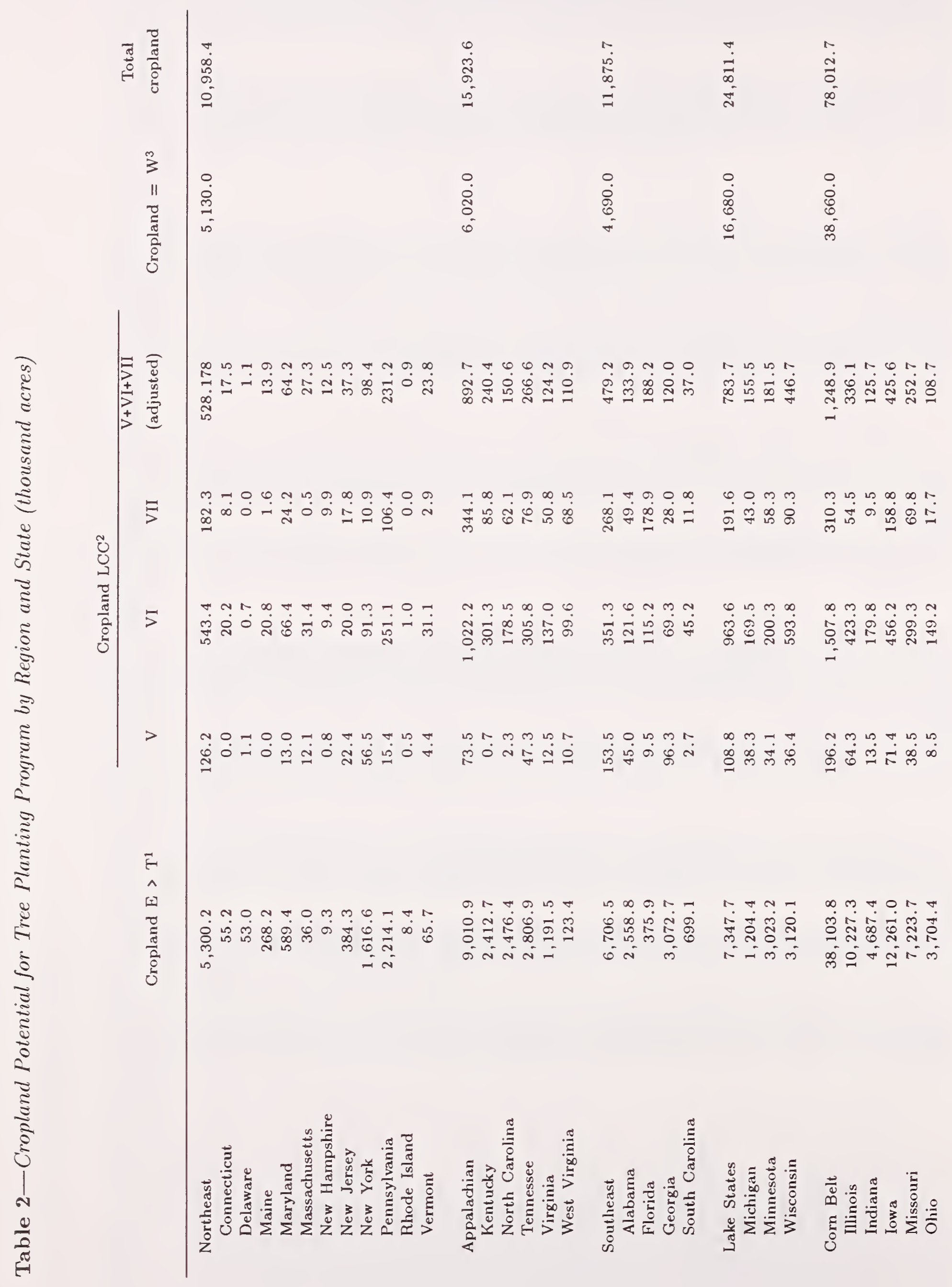




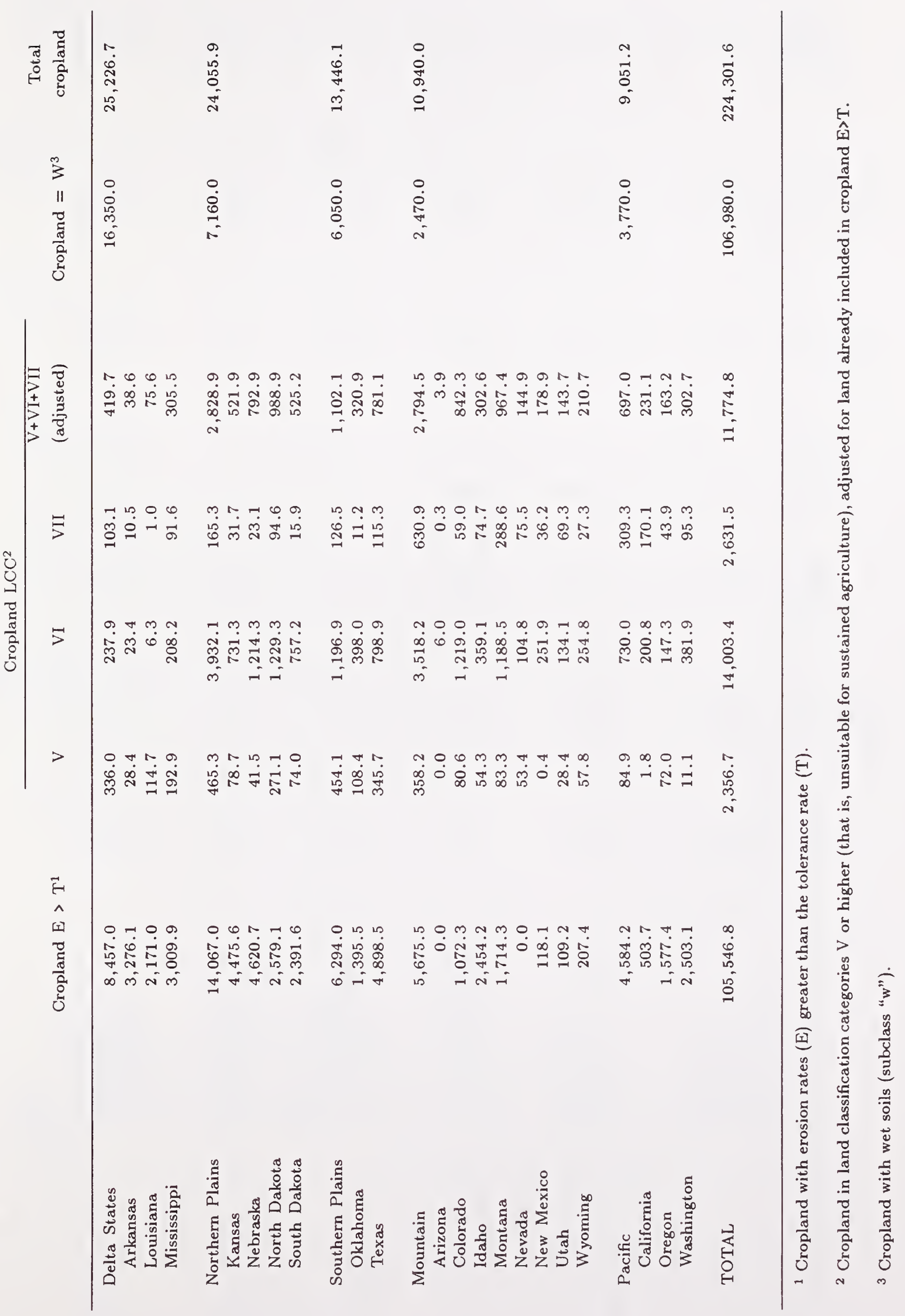




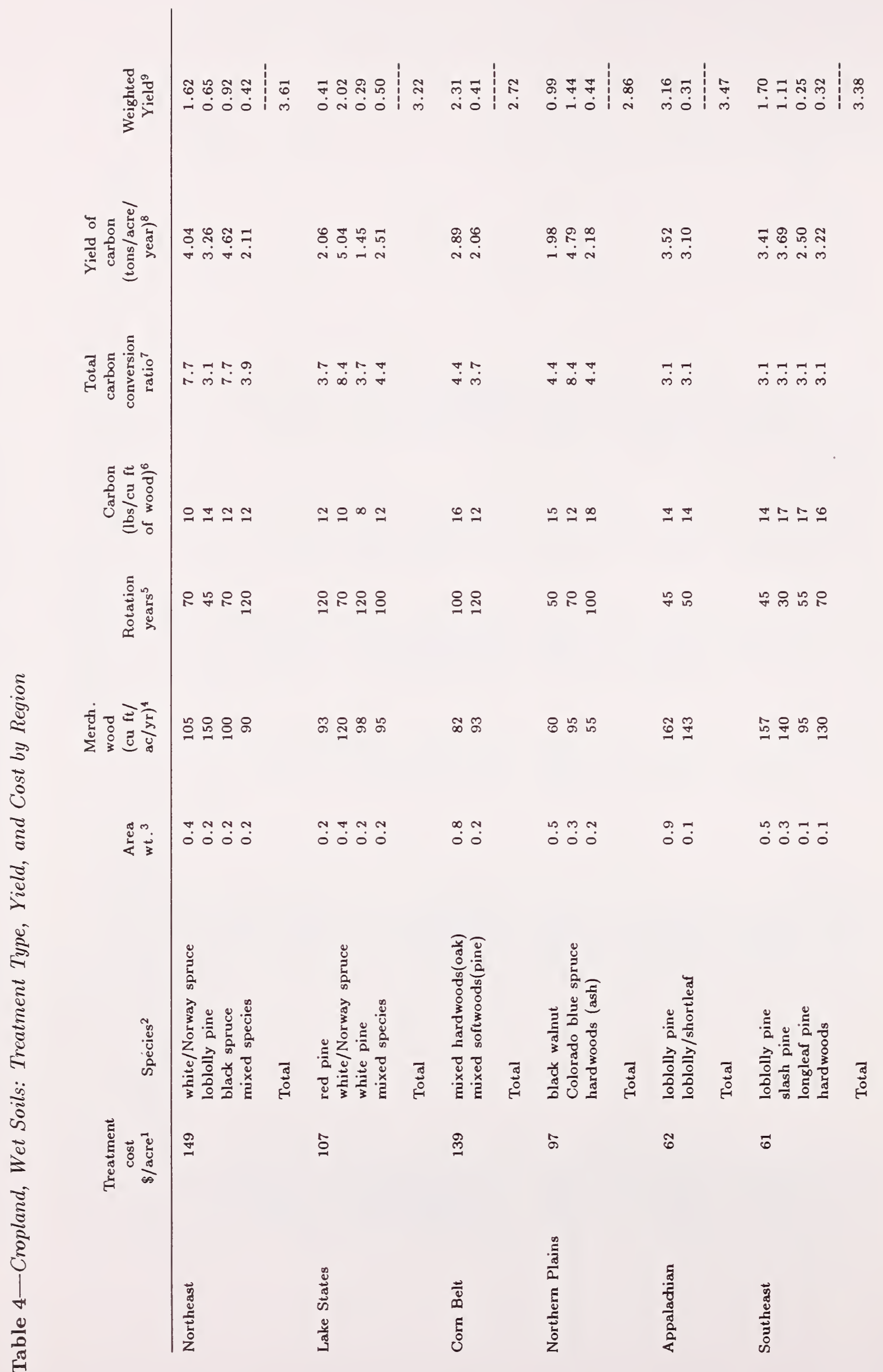




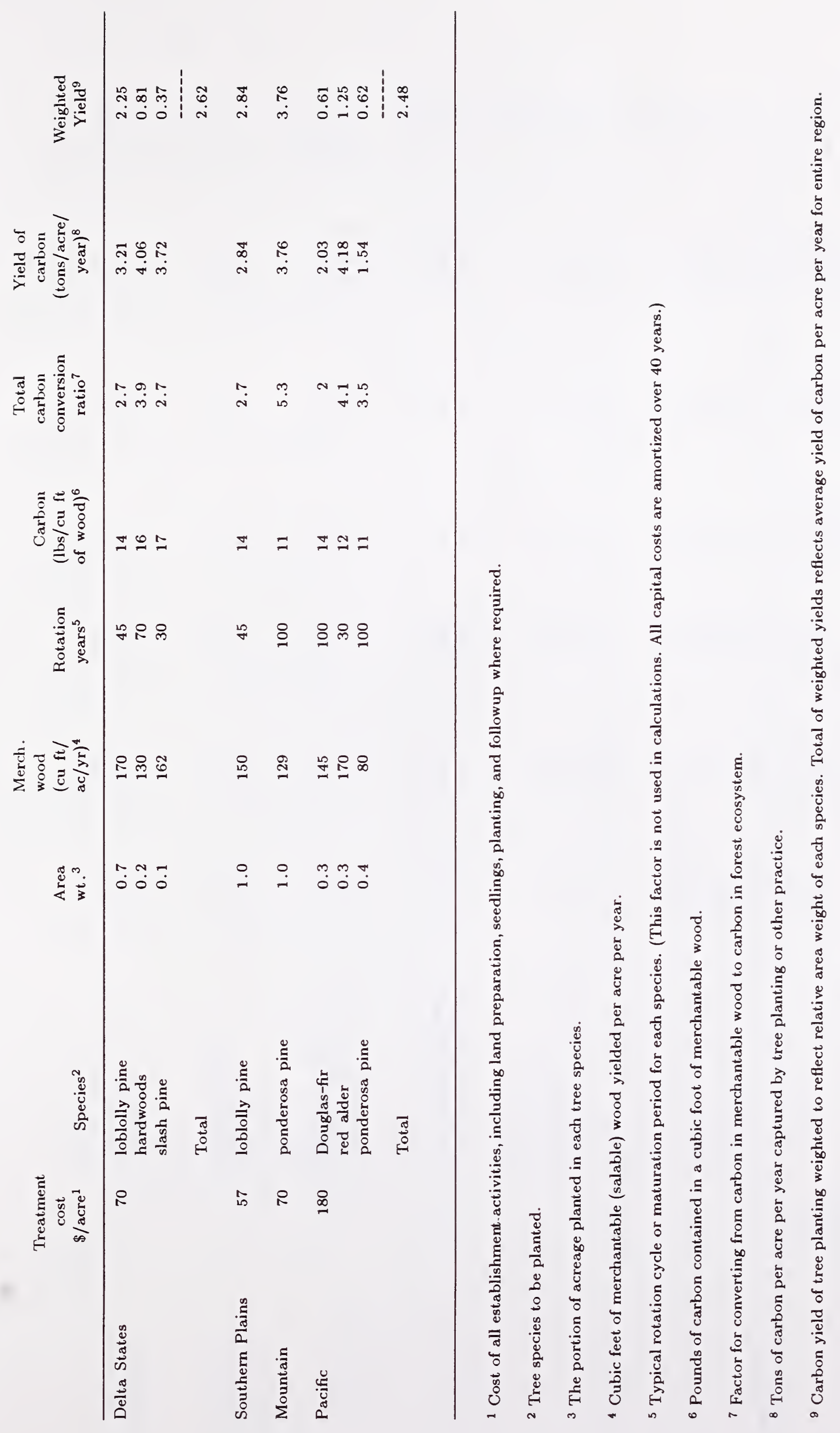




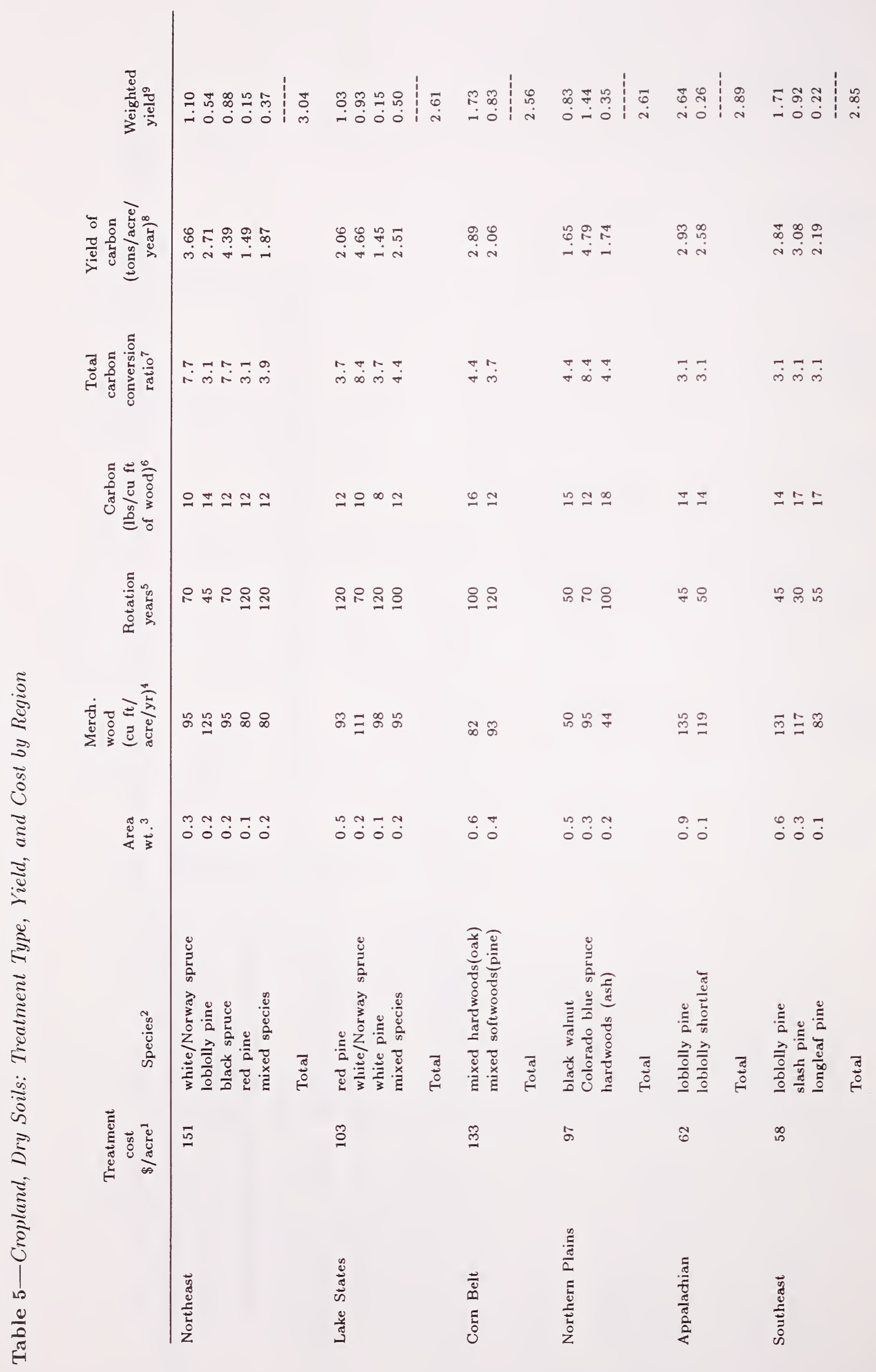




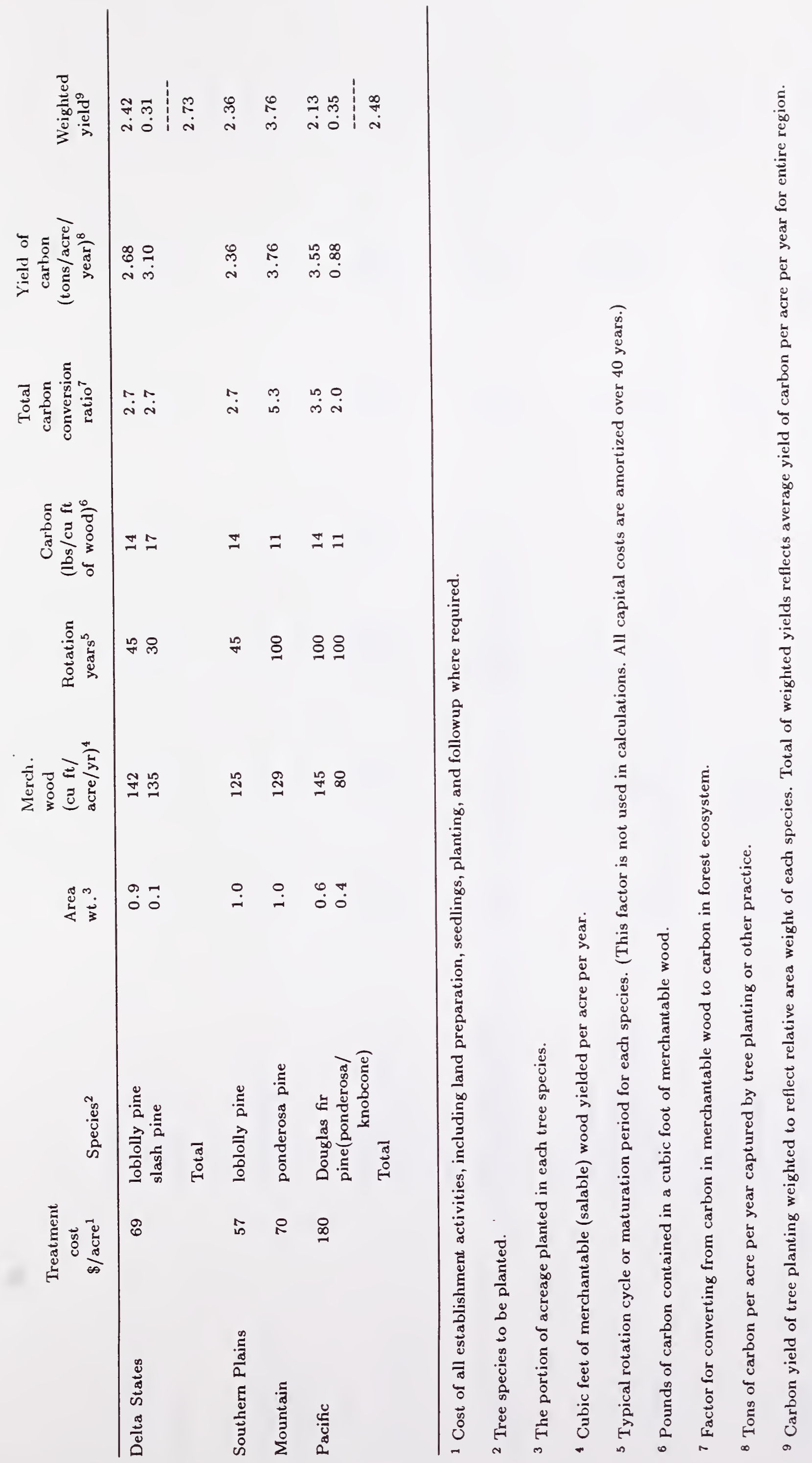




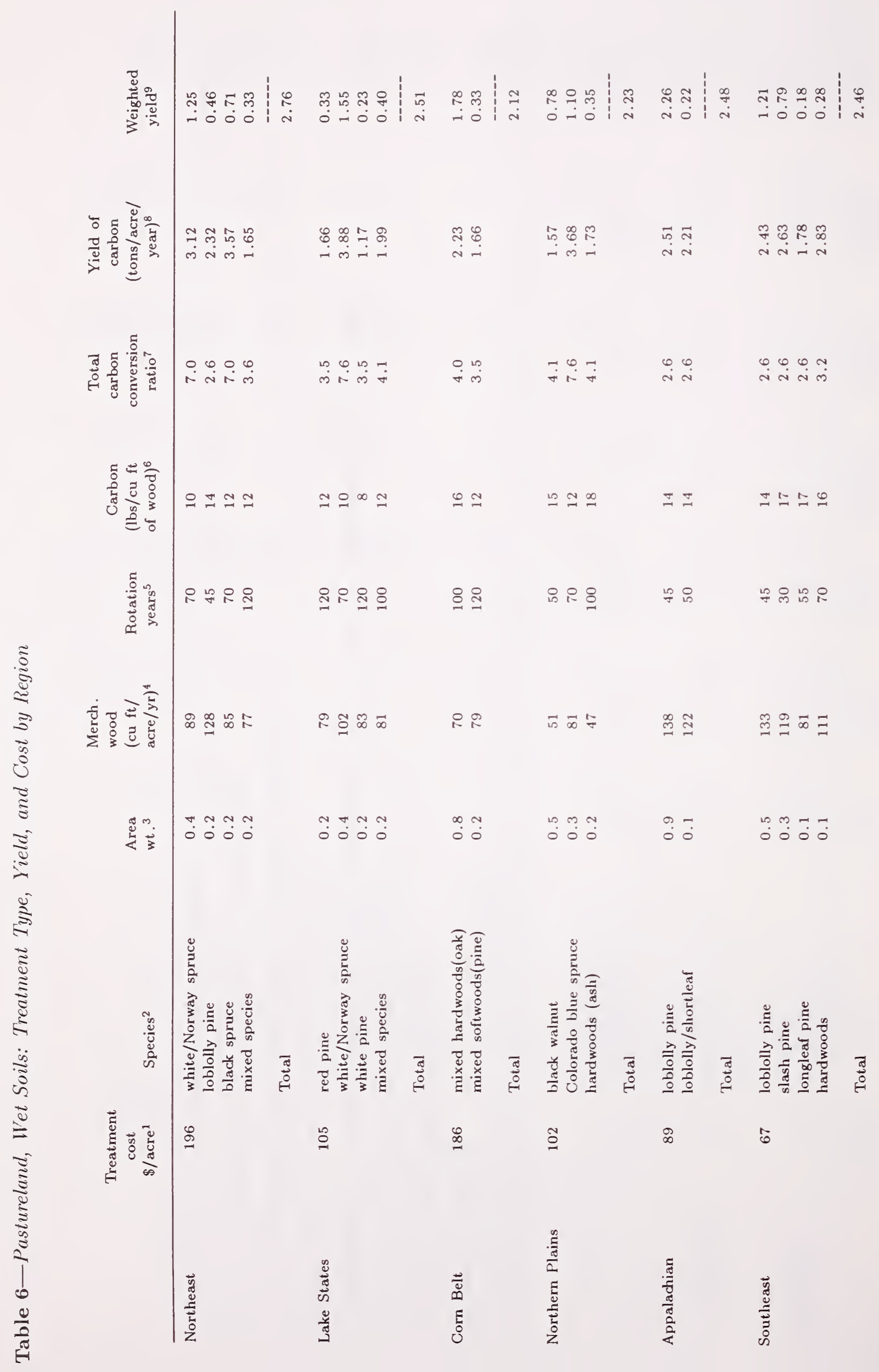




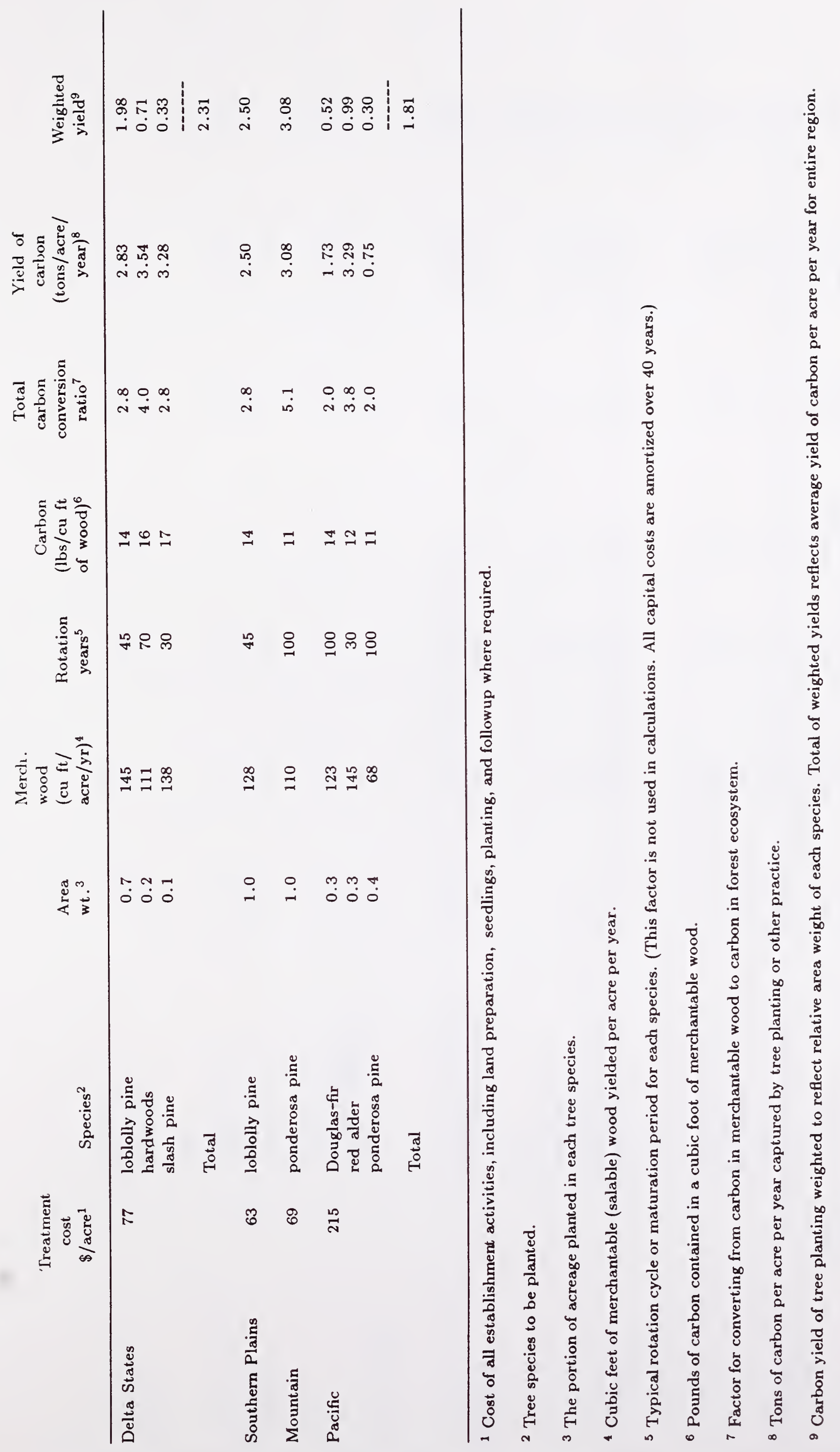




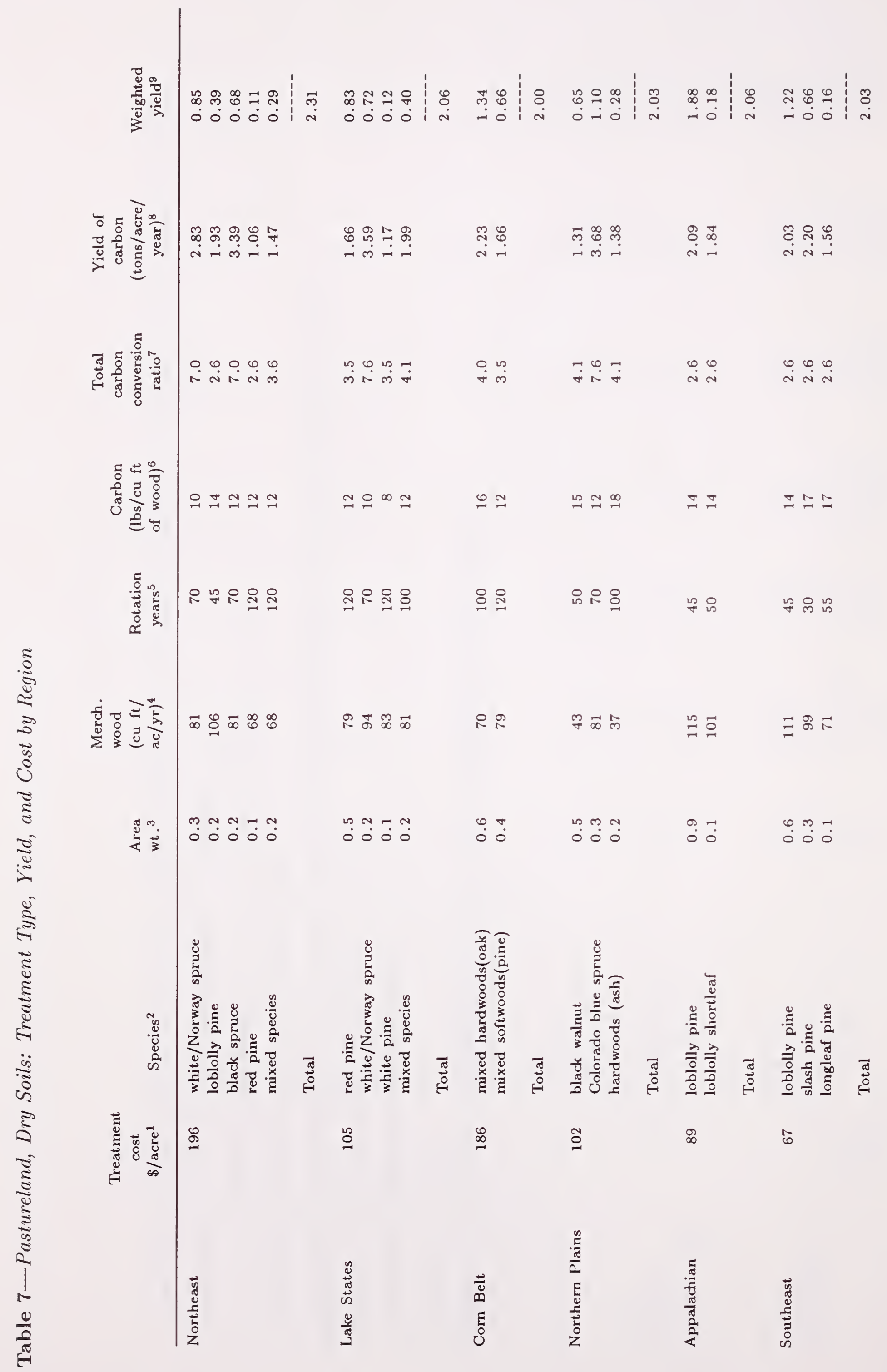




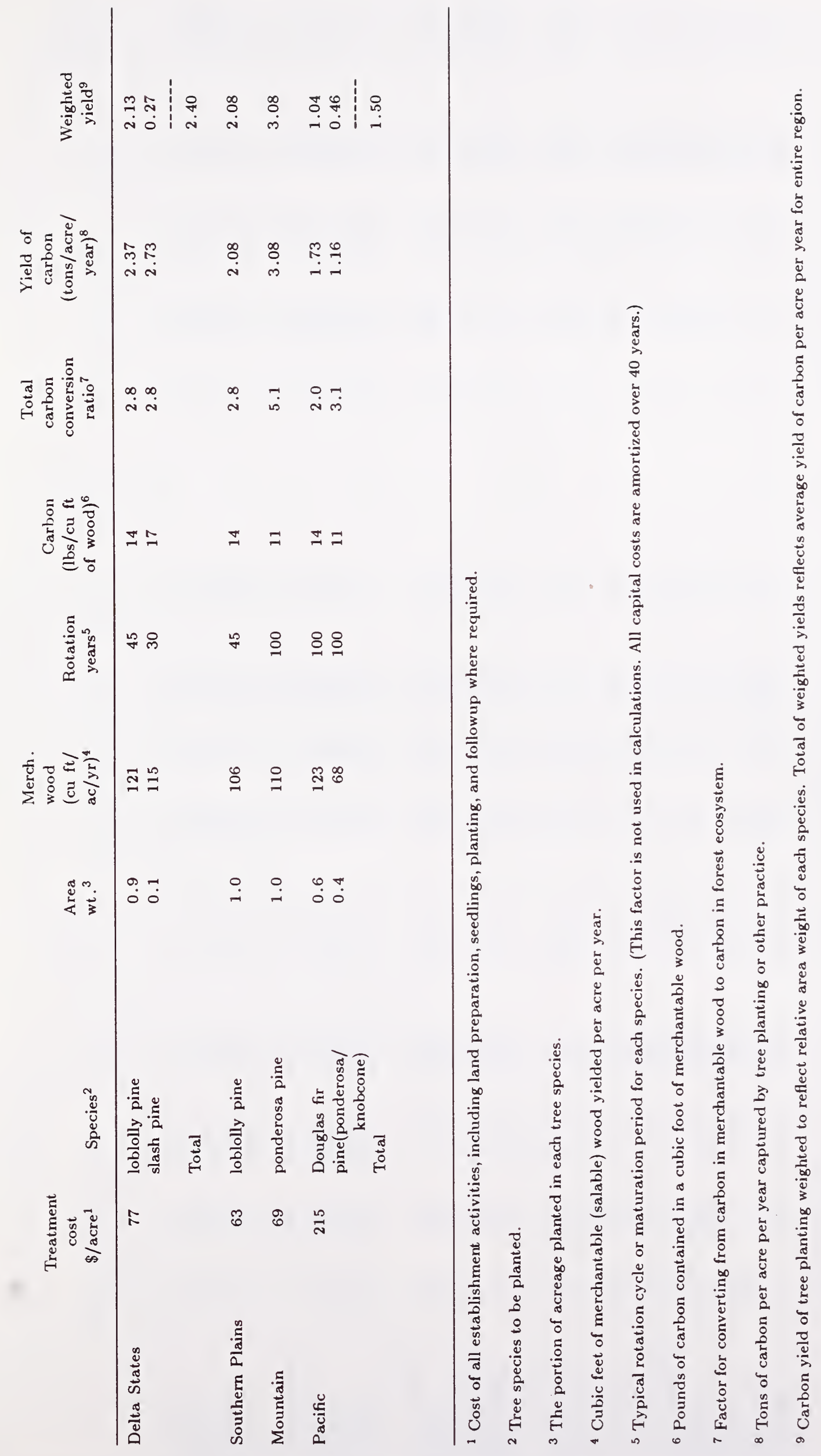




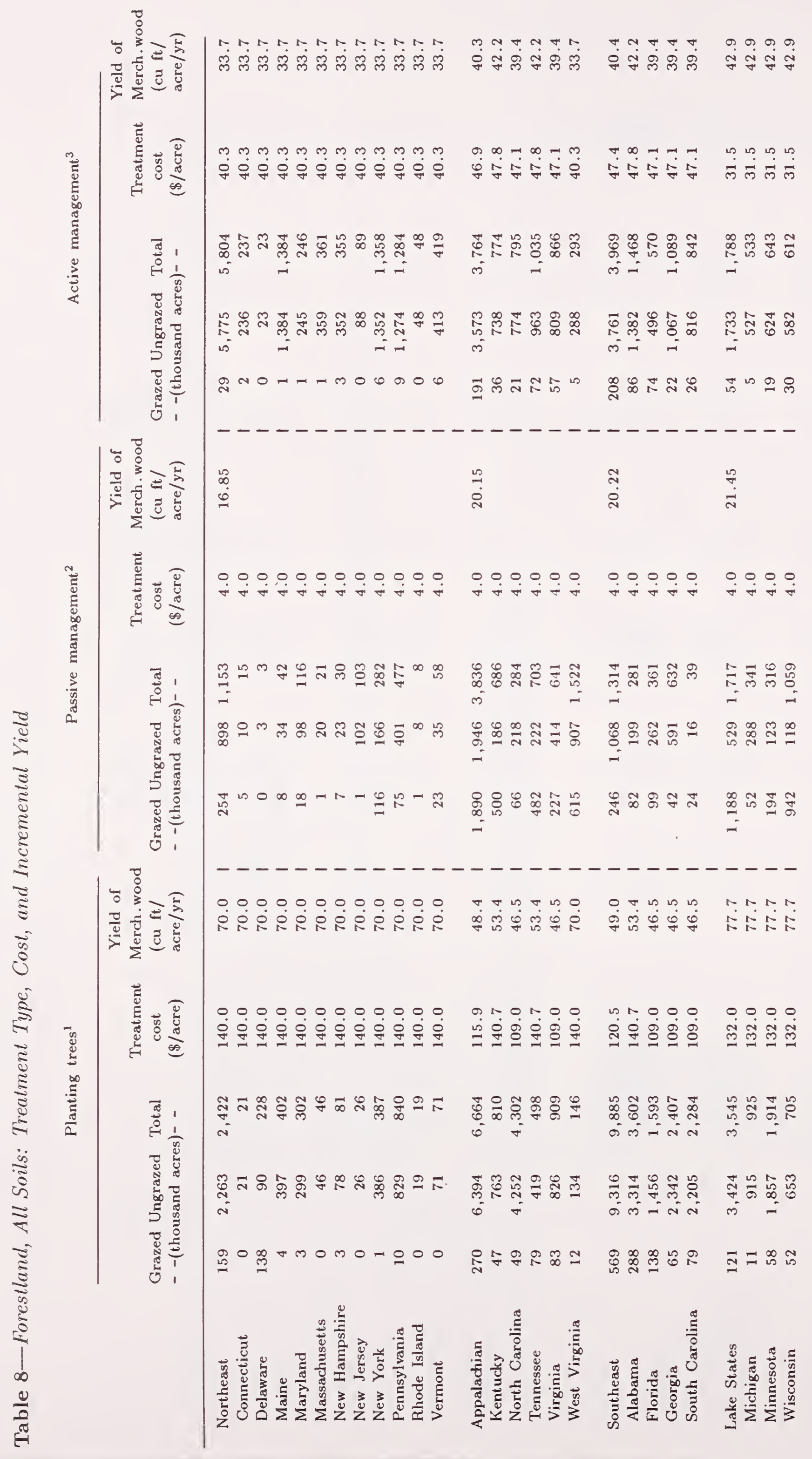




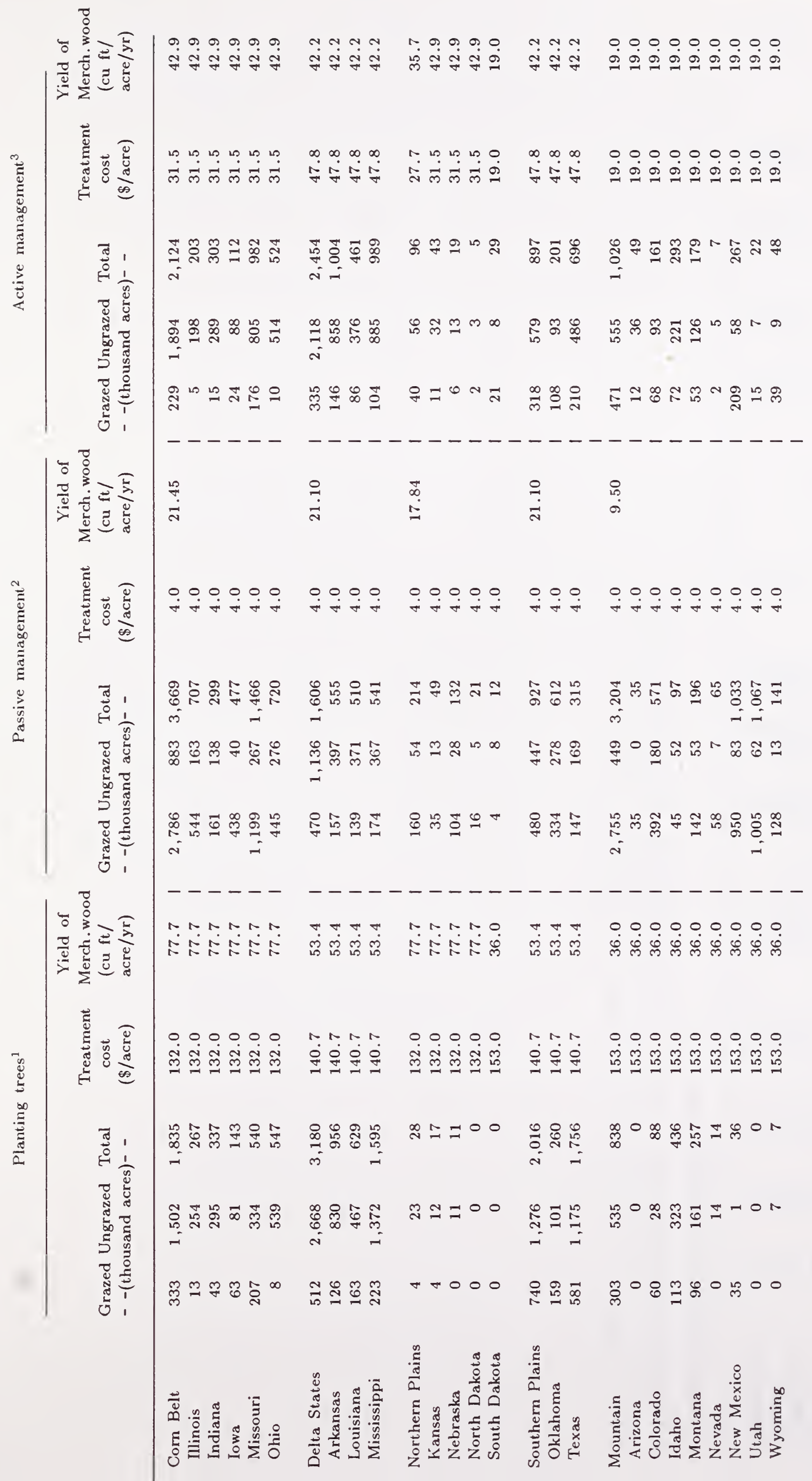




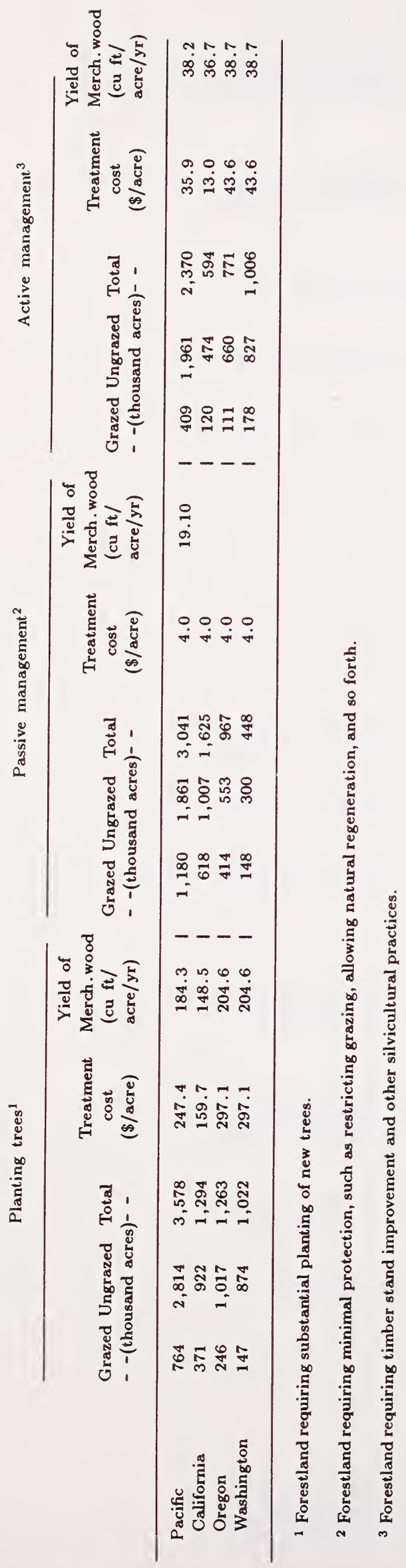




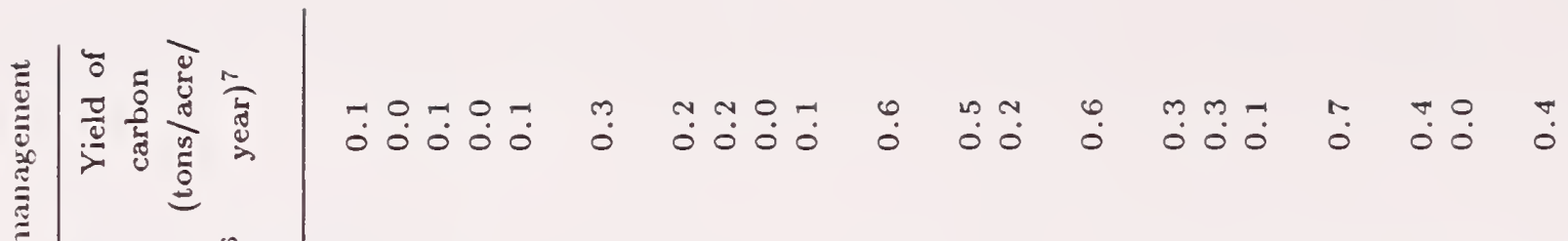

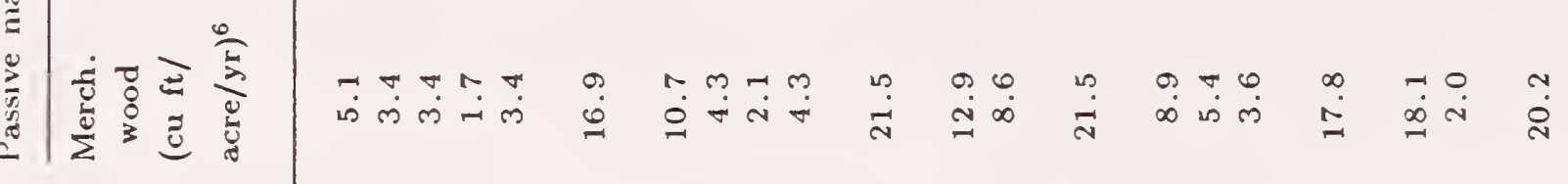

|

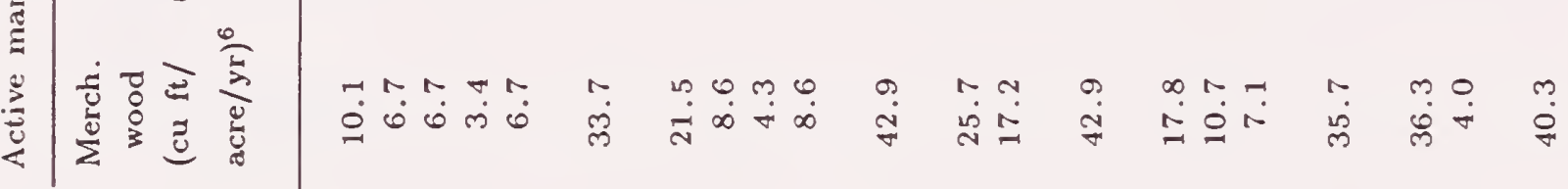

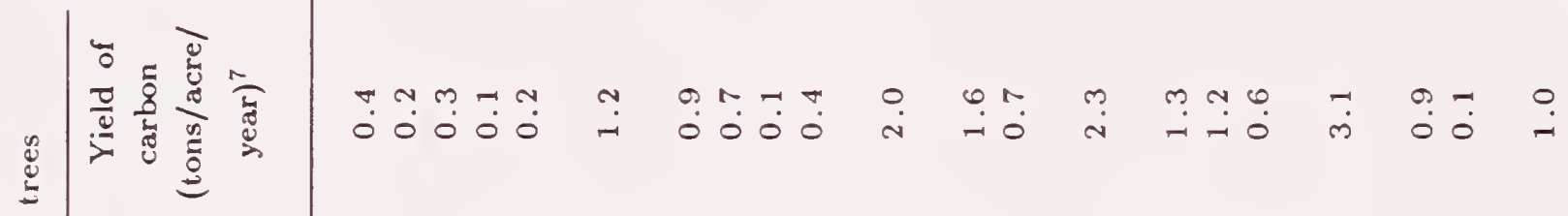

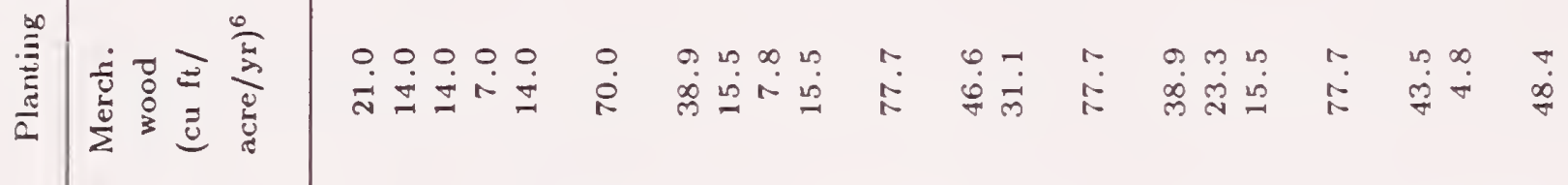

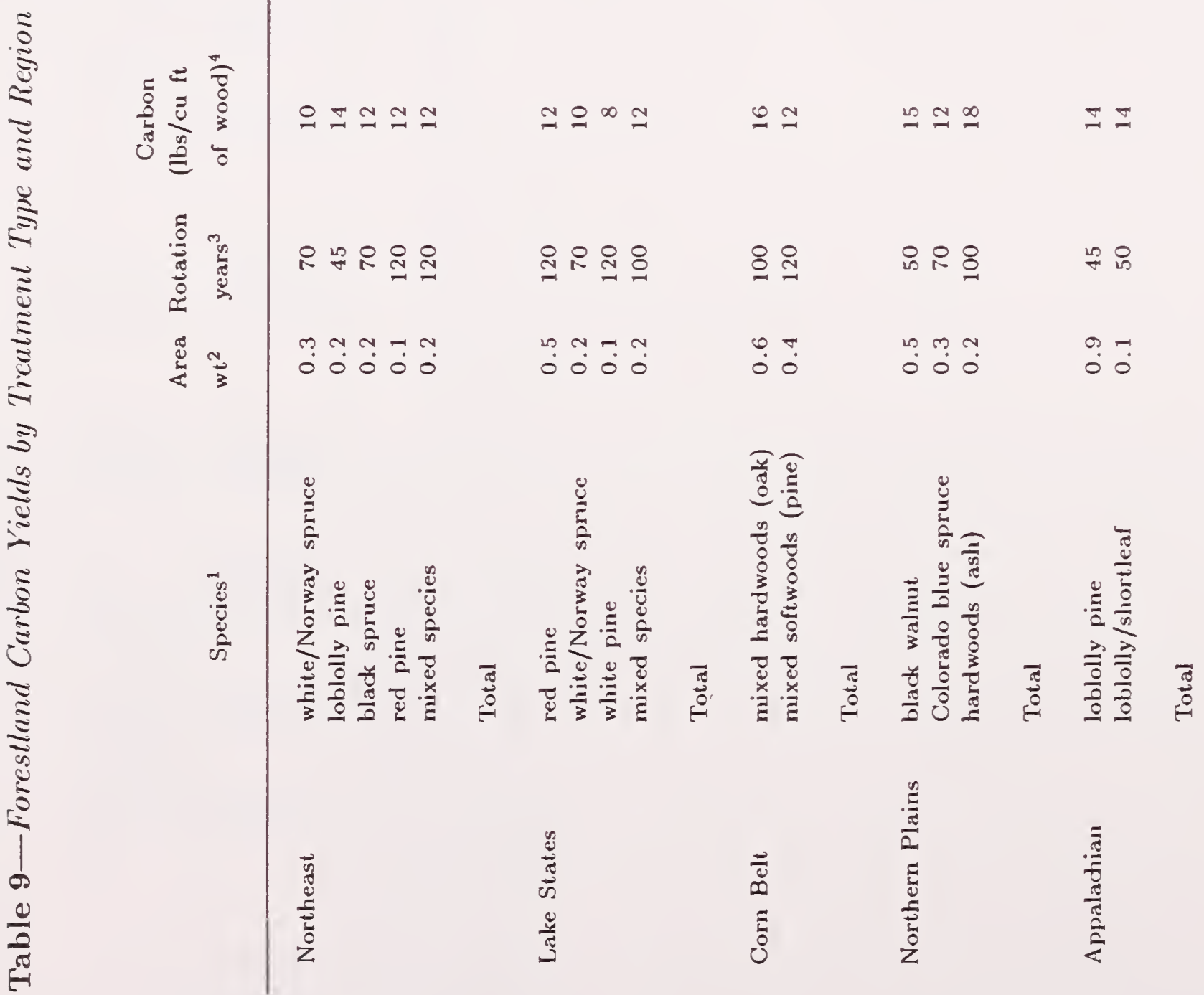




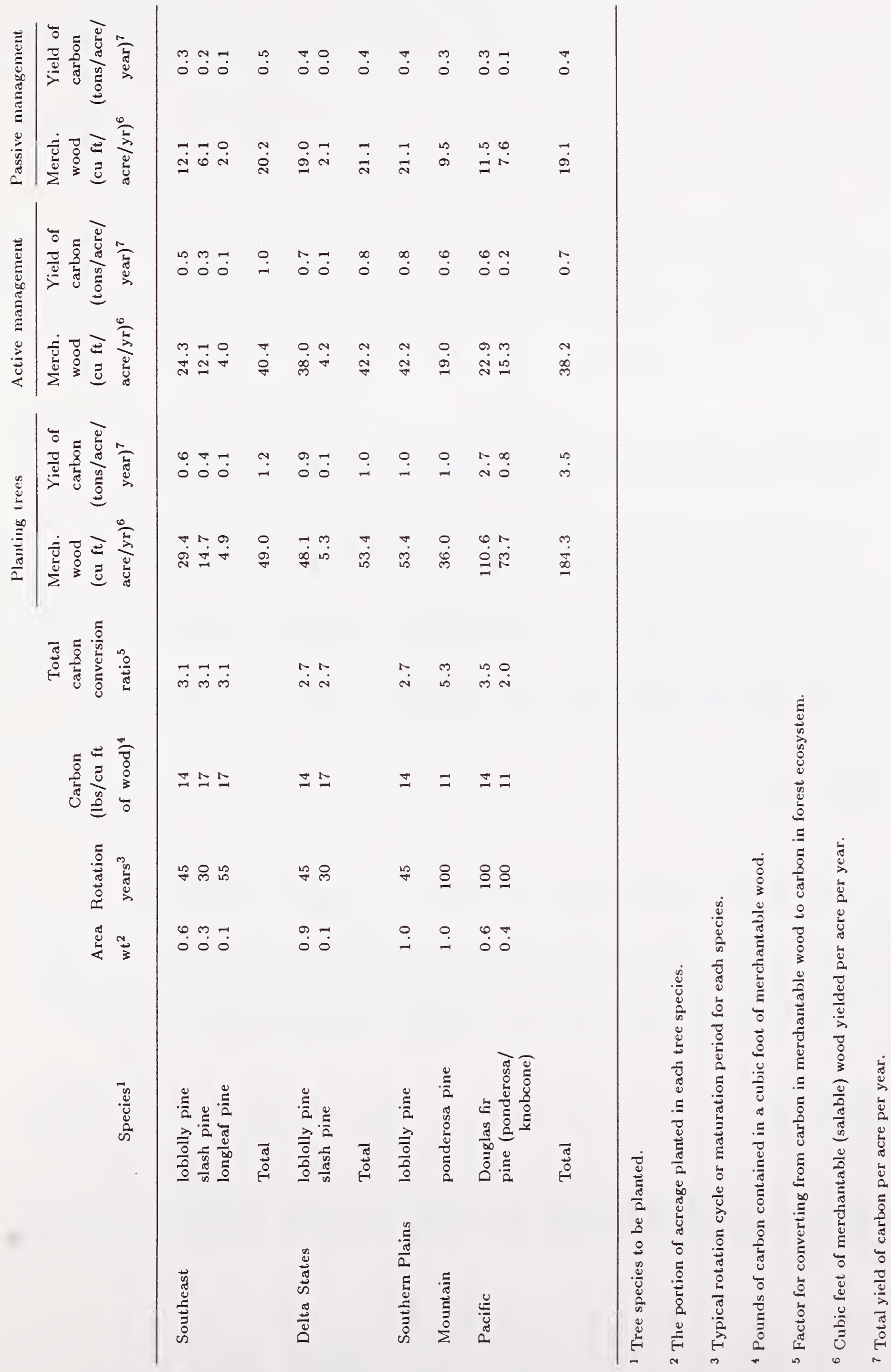




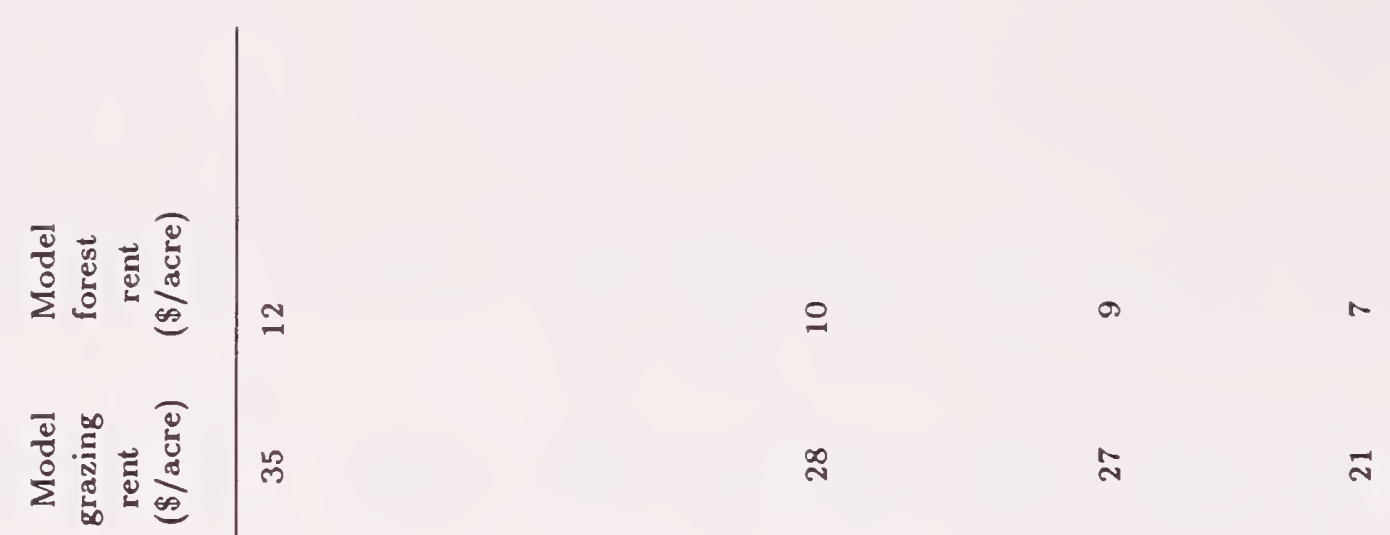

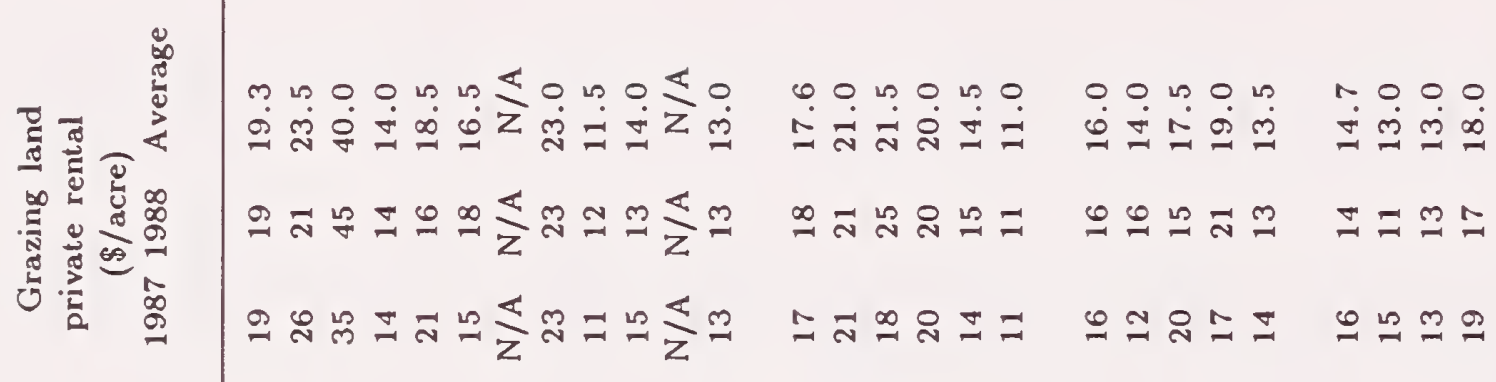

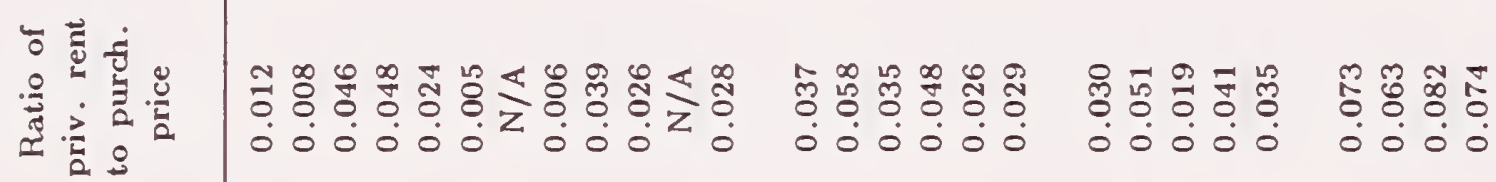

n

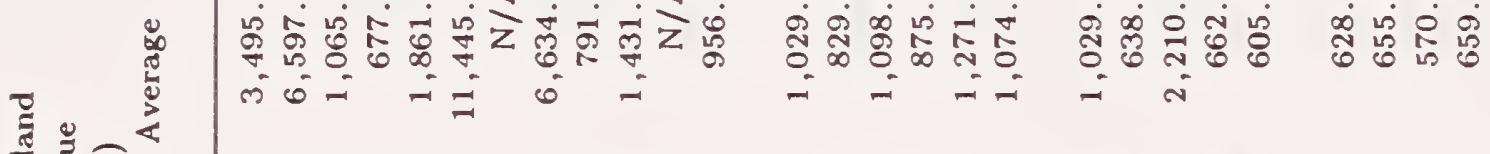

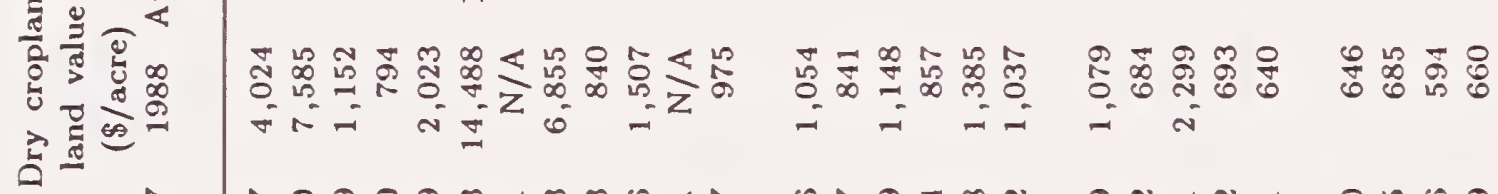

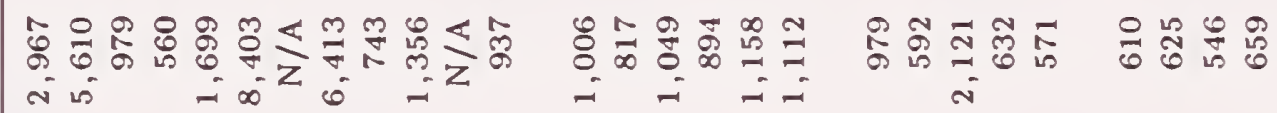

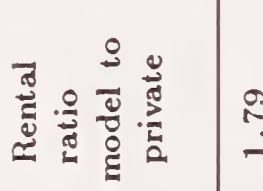

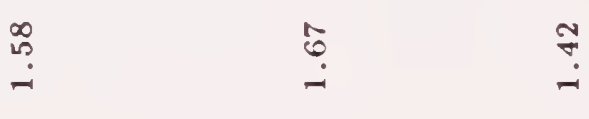

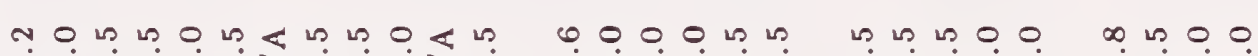

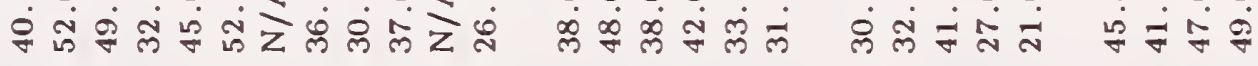

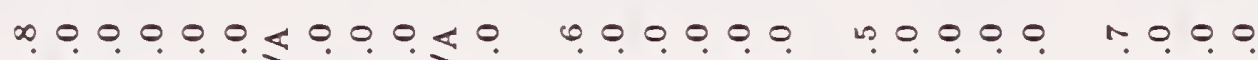

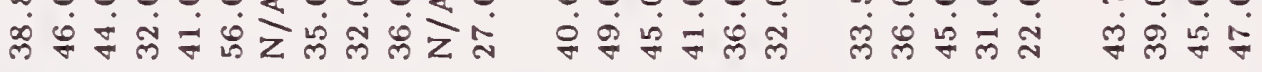

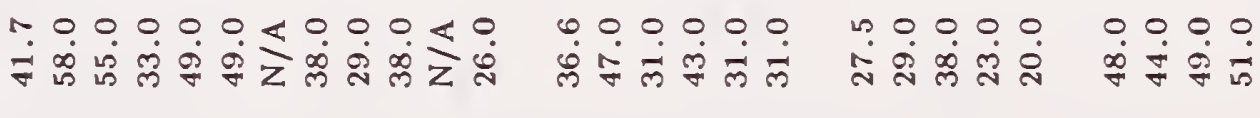

$\begin{array}{ll}1 & 8 \\ & 8 \\ 8 & 0\end{array}$

\begin{tabular}{lll}
8 & 8 & 8 \\
\hline 0 & $\frac{1}{6}$ & के
\end{tabular}

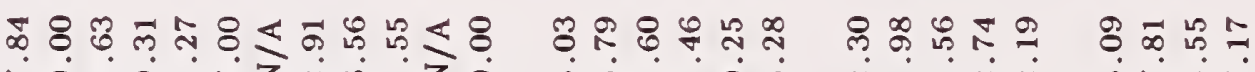

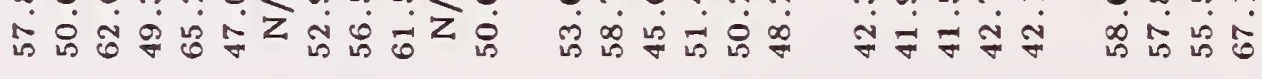

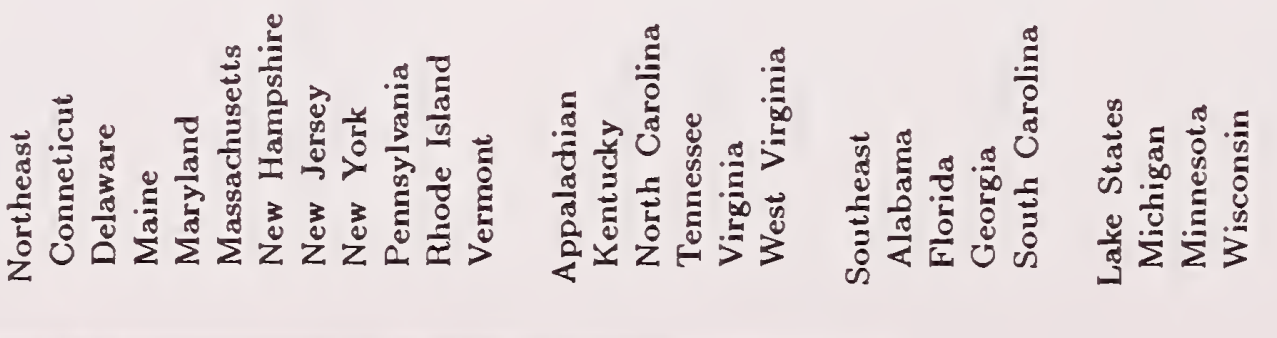




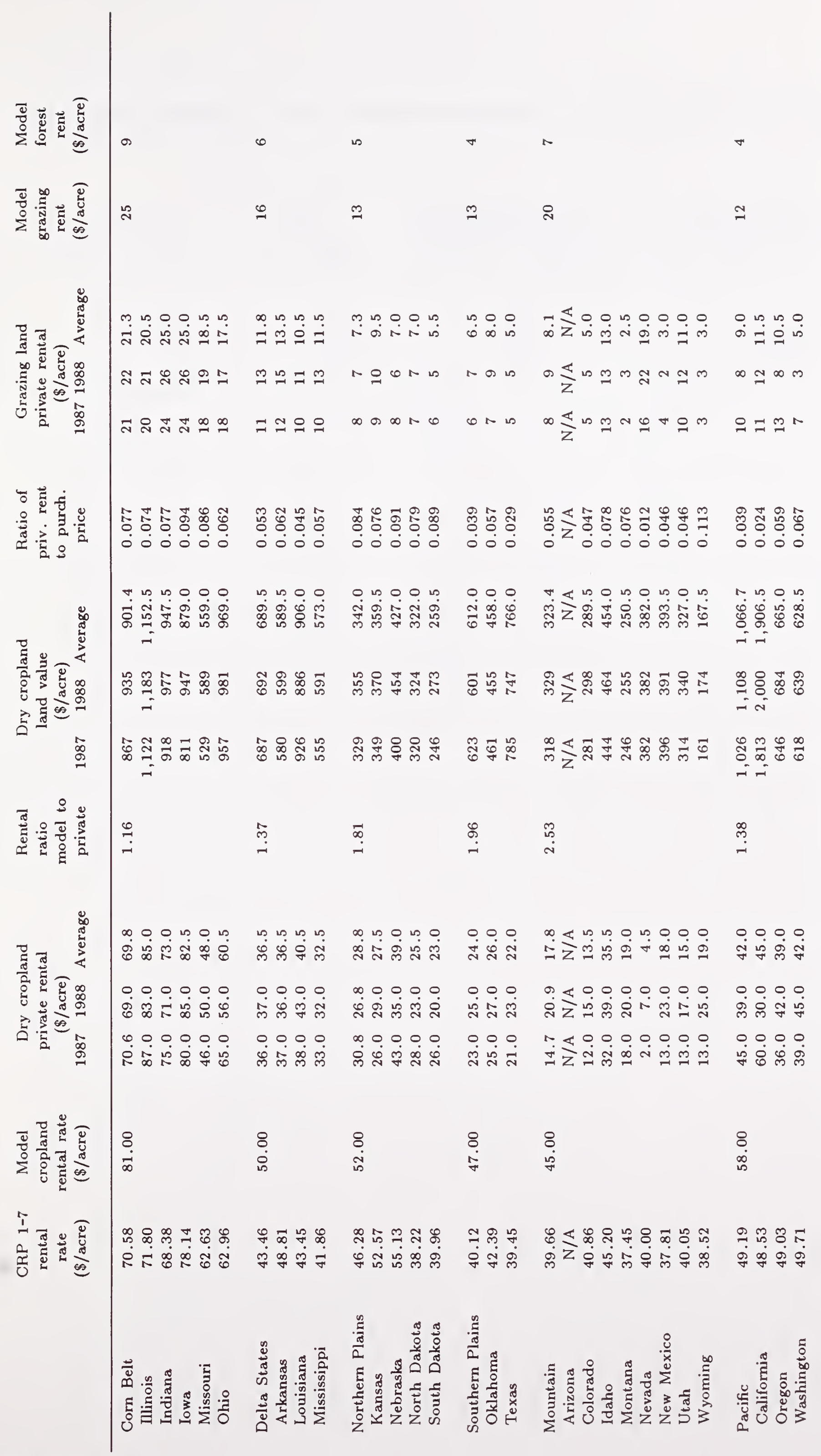


Table 11-Program Statistics by Percentage Reduction From 1.43 Billion Short Tons per Year

Annual $\mathrm{CO}_{2}$ offset (percent/millions of short tons)
Land requirement (millions of acres)
Total annual

cost

(billion \$)
Average cost

$(\$ /$ ton carbon)
36.9

70.9

138.4

197.6
0.7

1.7

4.5

7.7
9.72

12.02

15.73

17.91 
Table 12-Regional Land Areas by Percentage Reduction From 1.43 Billion Short Tons per Year

\begin{tabular}{|c|c|c|c|c|}
\hline & & Acres & ed in $f$ & \\
\hline & $5 \%$ & $10 \%$ & $20 \%$ & $30 \%$ \\
\hline Northeast & 0 & 0 & 1,707 & 4,129 \\
\hline Appalachia & 0 & 7,105 & 24,450 & 38,190 \\
\hline Southeast & 800 & 7,688 & 26,073 & 26,073 \\
\hline Lake States & 5,466 & 7,872 & 9,660 & 13,980 \\
\hline Corn Belt & 3,959 & 7,628 & 12,594 & 17,826 \\
\hline Delta States & 5,417 & 7,023 & 17,603 & 35,830 \\
\hline Northern Plains & 2,584 & 2,584 & 2,584 & 9,744 \\
\hline Southern Plains & 7,906 & 7,906 & 15,975 & 15,974 \\
\hline Mountain & 1,819 & 13,785 & 13,785 & 14,623 \\
\hline Pacific & 8,989 & 8,989 & 9,909 & 10,113 \\
\hline
\end{tabular}


Appendix B-Figures 


\section{USDA Farm Production Regions}

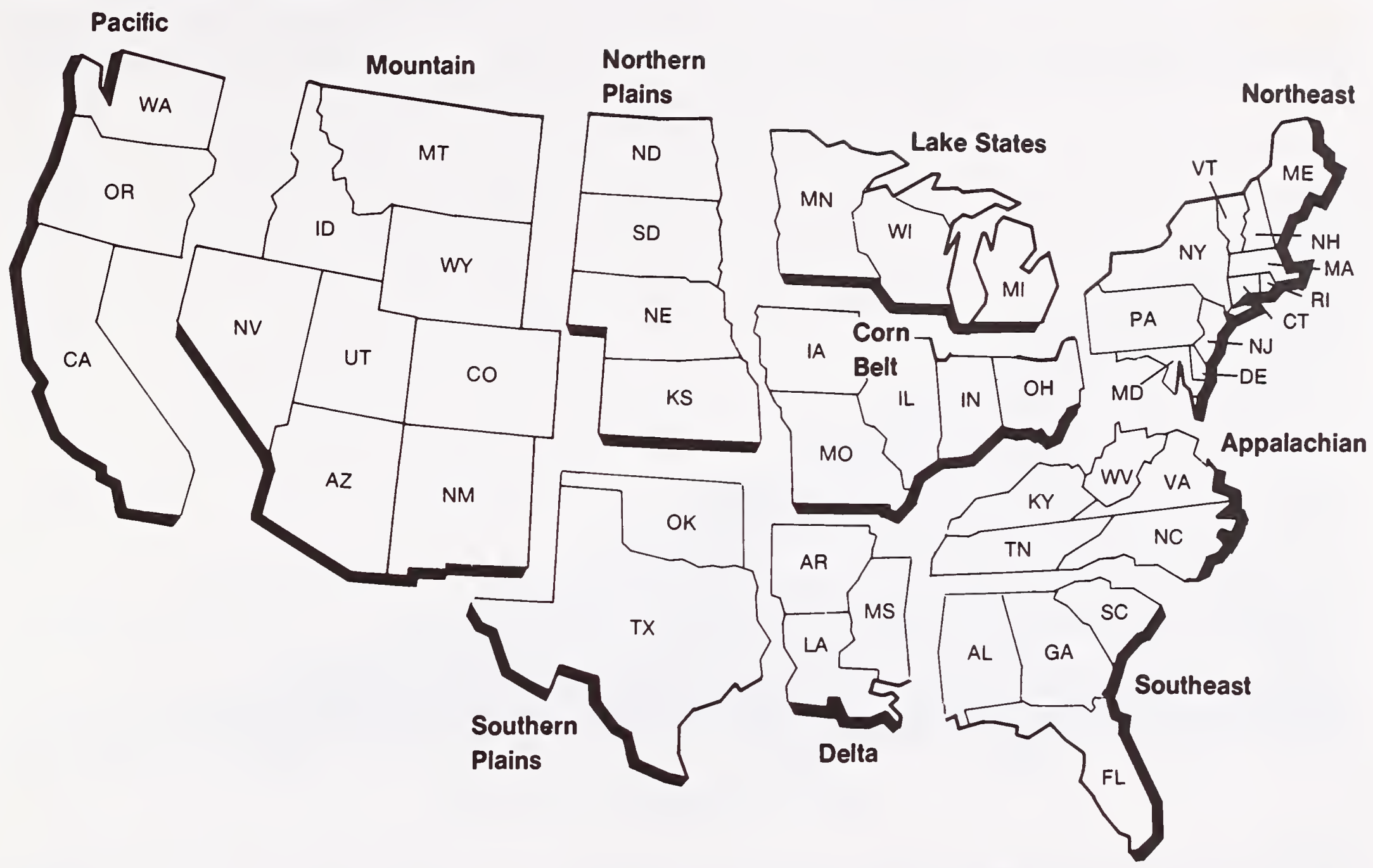

Figure 2

\section{Total Annual Cost of Carbon Sequestering}

Billions of Dollars

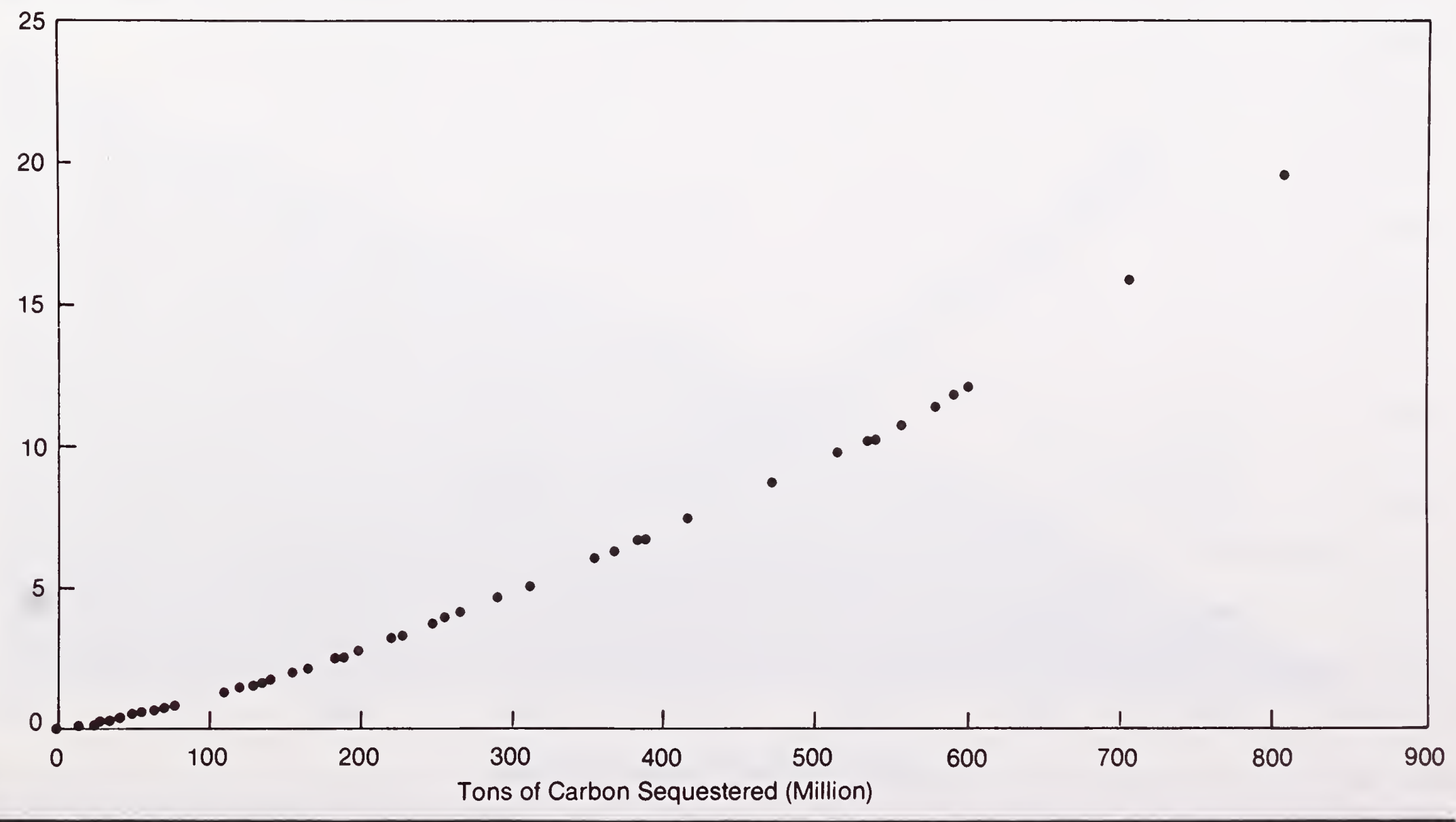


Figure 3

\section{Marginal Cost of Carbon Sequestering (Dollars/Ton of Carbon at Margin)}

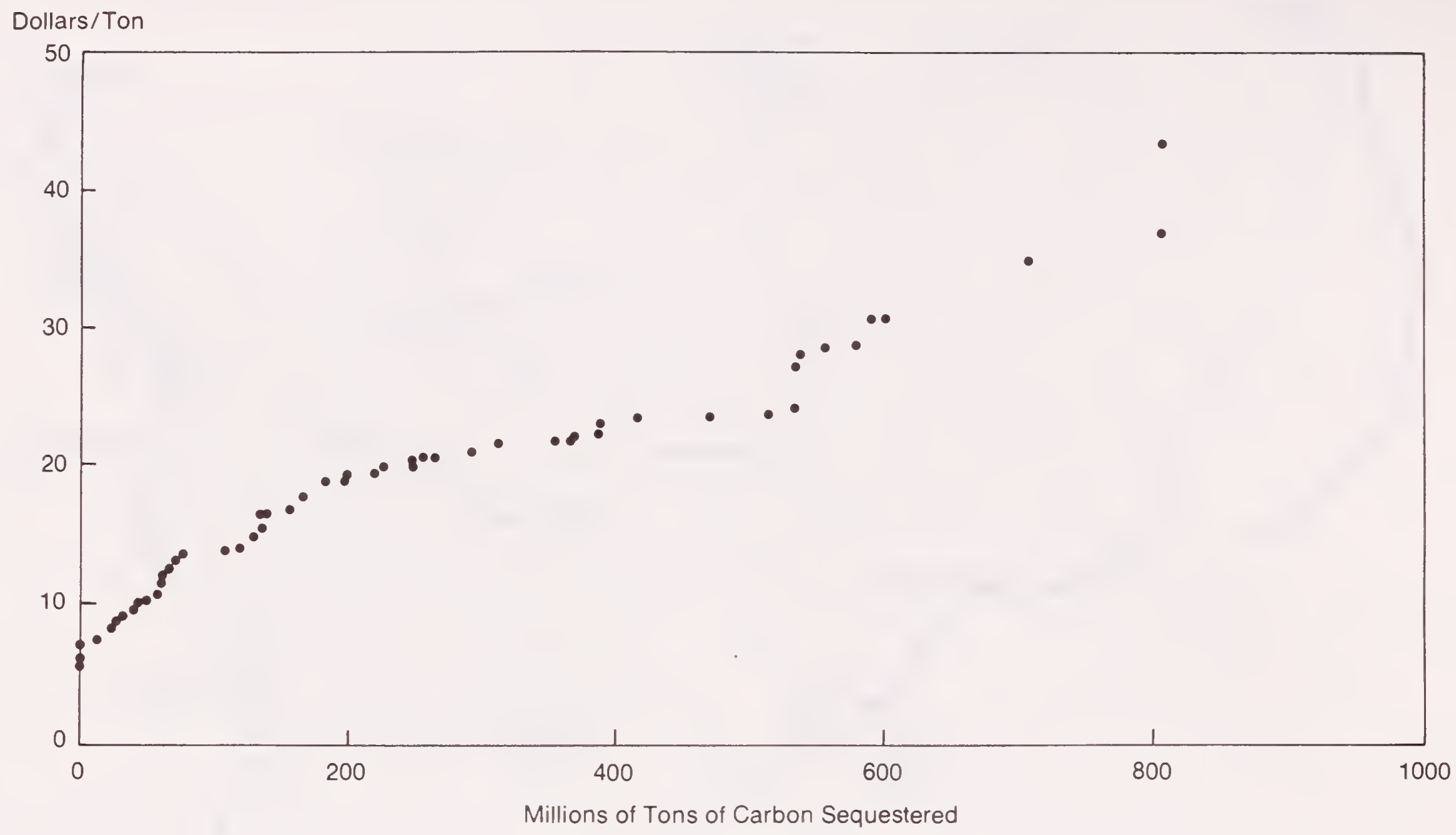

Figure 4

Acreage Requirements by Land Type (Millions of Acres)

Millions of Acres

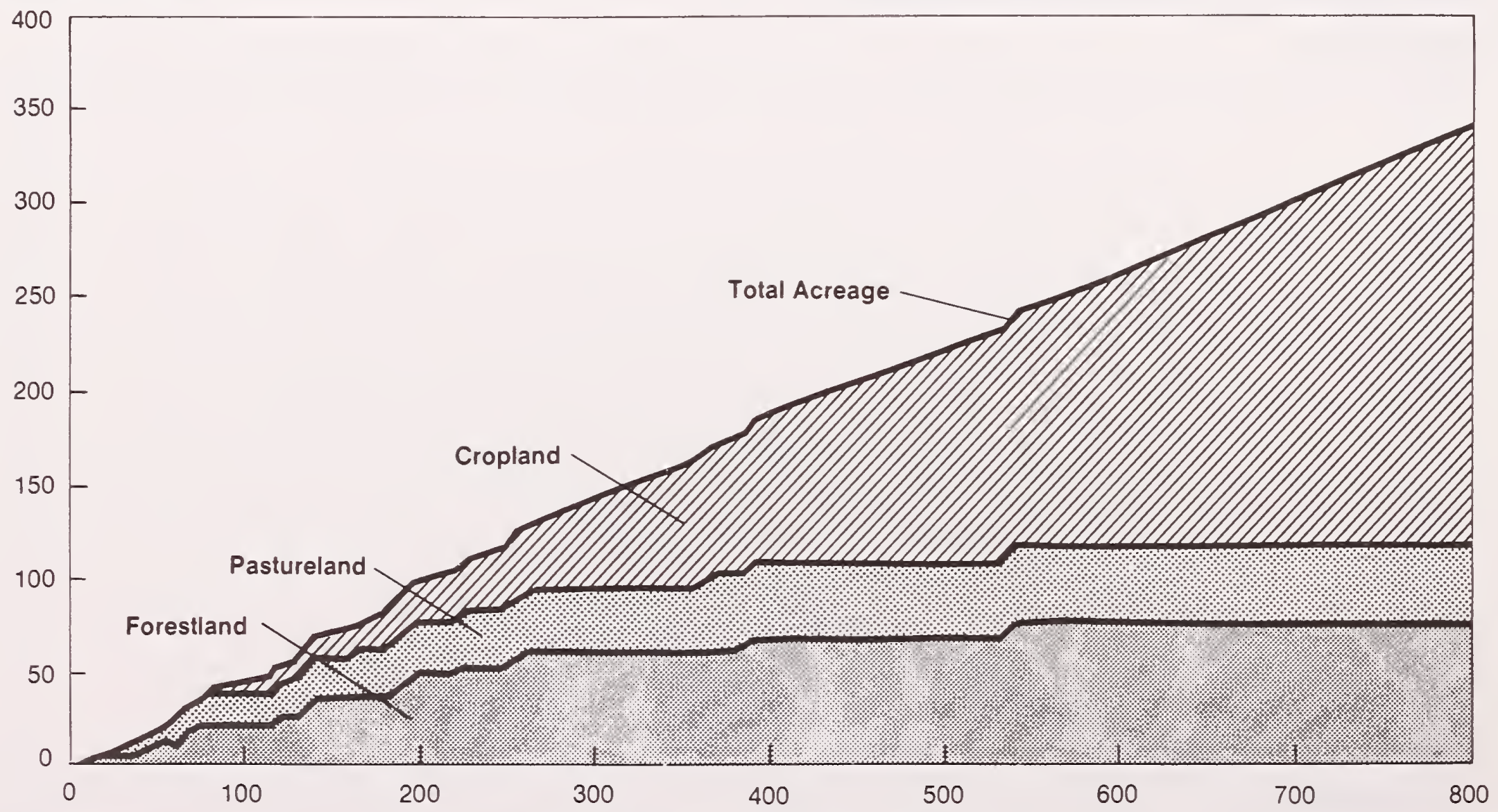

Millions of Tons of Carbon Sequestered 


\section{Carbon Sequestration by Land Type (Millions of Tons of Carbon Annually)}

Millions of Tons of Carbon Sequestered

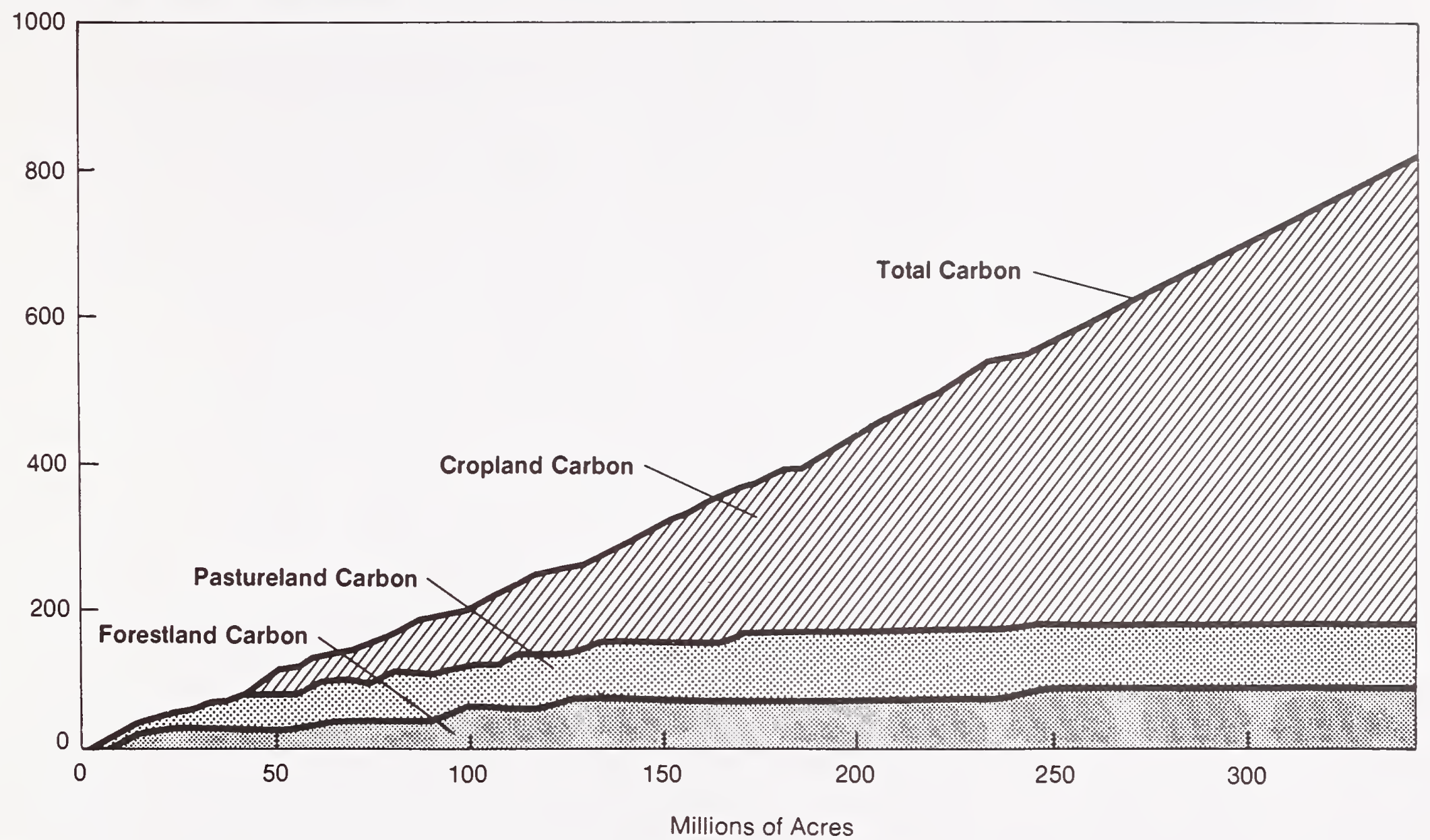

Figure 6

\section{Effect of Discount Rate on Total Costs, Capital Recovery Over 40 Years}

Billions of Dollars Annually

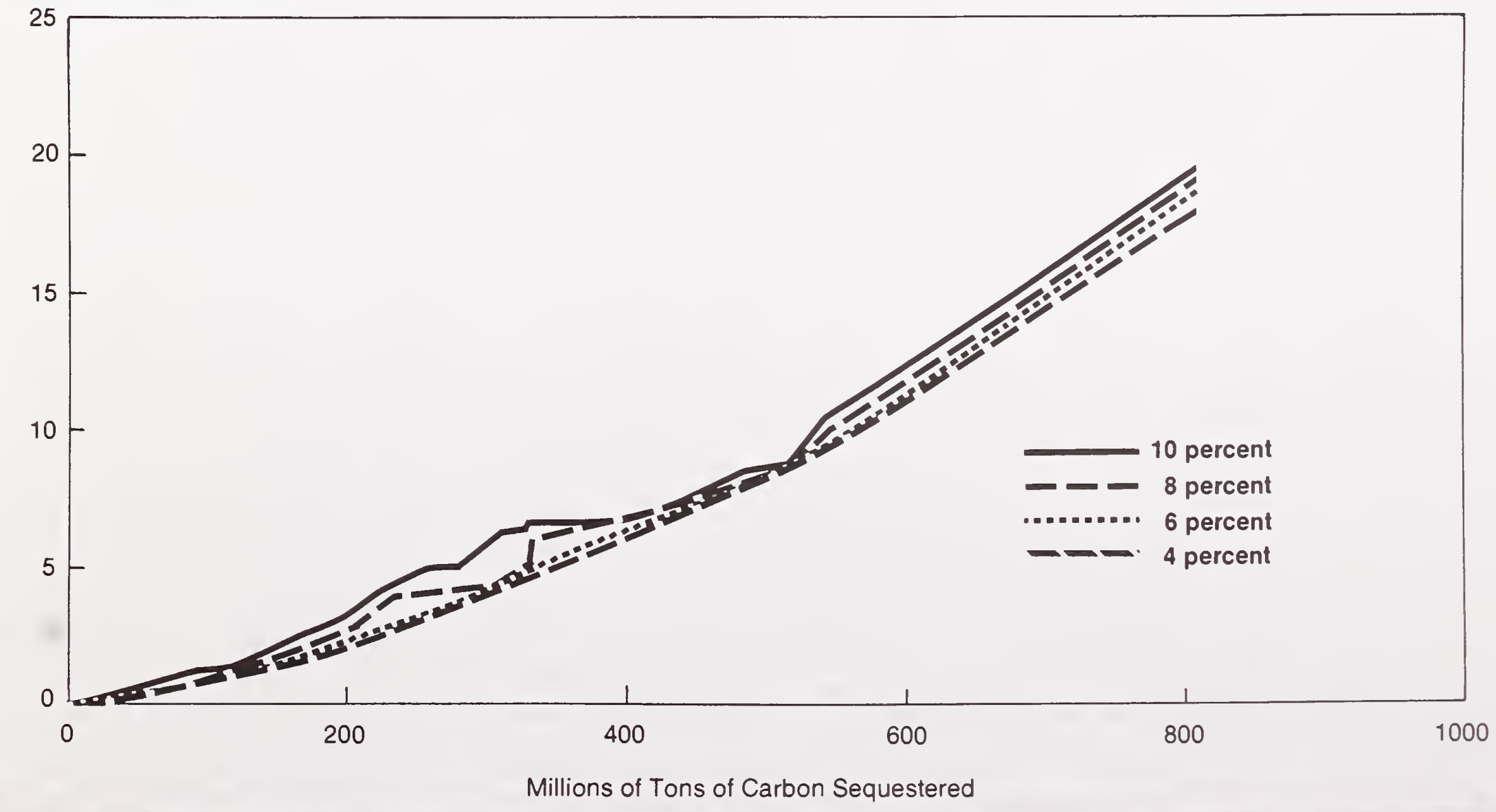





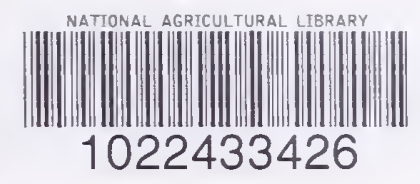


